\title{
OPEN A synthesis and future research directions for tropical mountain ecosystem restoration
}

\begin{abstract}
Tina Christmann $\mathbb{D}^{1,2 \bowtie}$ \& Imma Oliveras Menor $\mathbb{D}^{1}$
Many tropical mountain ecosystems (TME) are severely disturbed, requiring ecological restoration to recover biodiversity and ecosystem functions. However, the extent of restoration efforts across TMEs is not known due to the lack of syntheses on ecological restoration research. Here, based on a systematic review, we identify geographical and thematic research gaps, compare restoration interventions, and consolidate enabling factors and barriers of restoration success. We find that restoration research outside Latin-America, in non-forested ecosystems, and on socio-ecological questions is scarce. For most restoration interventions success is mixed and generally limited by dispersal and microhabitat conditions. Finally, we propose five directions for future research on tropical mountain restoration in the UN decade of restoration, ranging from scaling up restoration across mountain ranges, investigating restoration in mountain grasslands, to incorporating socioeconomic and technological dimensions.
\end{abstract}

Tropical mountain ecosystems (TME) are hotspots of biodiversity ${ }^{1,2}$ and endemism ${ }^{3}$ and are located in tropical latitudes between 1000 and $4000 \mathrm{~m}$ asl, and the elevation gradients give rise to a variety of ecosystems including montane forests, montane cloud forests, forest-grassland treelines, mountain grasslands and azonal formations (Table 1). TME span across all continents in the tropical belt, and despite their small spatial extent of just over 4 million $\mathrm{km}^{2}$ (Table 1) they provide numerous ecosystem services to people and society, including carbon sequestration, water regulation and supply, timber and food provision, erosion control, and cultural services ${ }^{4}$.

Notwithstanding their tremendous biological importance and complexity, TME are still relatively understudied compared to temperate mountain systems ${ }^{5}$. In recent decades, TME have been experiencing increasing pressure from multiple external drivers and stressors, such as anthropogenic pressures due to agricultural encroachment, pasture conversion and population growth ${ }^{6}$, exotic plantations ${ }^{7,8}$, invasion by exotic animals ${ }^{9}$ and exotic plants ${ }^{10-12}$, as well as accelerating climate change impacts ${ }^{13}$. These drivers lead to severe degradation in TME, impacting all levels of ecological organization, such as disruption of ecosystem services, losses in community diversity, changes in species interactions, reductions of population sizes and lowered genetic diversity ${ }^{14}$. Degradation in TME is far-reaching and ubiquitous: Tovar et al. ${ }^{15}$ projected that climate change will alter 3-7\% of tropical Andean biomes, resulting in a 31.4\% loss in extent of high-altitudinal Páramo grasslands due to replacement by montane forests by 2039 . Further, Helmer et al. ${ }^{16}$ indicate that in the next $25-45$ years, reductions in cloud immersion are estimated to diminish $57-80 \%$ of Neotropical montane cloud forests. Hall et al. ${ }^{17}$ estimate that the Tanzanian Eastern Arc mountains have lost 25\% of forested areas since 1955, with deforestation rates of $57 \%$ in sub-montane forests $(800-1200 \mathrm{~m})$.

At the same time, socio-economic drivers have led to migrations of people from tropical mountains to urban areas, abandoning many previously cultivated and inhabited areas ${ }^{24-26}$ and creating a large opportunity for ecosystem recovery and restoration across many TME.

Restoration of biodiverse ecosystems, such as TME, has the potential to simultaneously recover lost biodiversity and ecosystem functioning and improve local livelihoods ${ }^{27}$, and has recently come to the fore of global conservation efforts ${ }^{28}$. Restoration is defined as "the process of assisting the recovery of an ecosystem that has been degraded, damaged or destroyed" 29 and, as such, encompasses a broad suite of approaches ranging from passive restoration, to assisted recovery and active restoration. The urgency for global restorative actions culminated in global restoration pledges like the 2011 Bonn Challenge and the proclamation of the UN Decade of Ecosystem Restoration. Motivations to restore damaged ecosystems include conserving biodiversity (specific habitats or species), enhancing ecosystem processes (such as nutrient cycling), combatting climate change (through carbon

${ }^{1}$ School of Geography and the Environment, Environmental Change Institute, University of Oxford, South Parks Road, Oxford OX1 3OY, UK. ${ }^{2}$ Worcester College, 1 Walton Street, Oxford OX12HB, UK. ${ }^{\square}$ email: tina.christmann@ worc.ox.ac.uk 


\begin{tabular}{|c|c|c|c|c|}
\hline Ecosystem & Description & Examples of sub ecosystems & Elevation & $\begin{array}{l}\text { Total area }\left(\mathrm{km}^{2}\right) \text { across the } \\
\text { tropics }\end{array}$ \\
\hline \multirow{3}{*}{ Mountain grasslands } & \multirow{3}{*}{$\begin{array}{l}\text { Grass-dominated systems found } \\
\text { above the treeline. Highly biodi- } \\
\text { verse with adaptations to strong } \\
\text { abiotic stressors, such as tussock } \\
\text { growth or conservative functional } \\
\text { traits }^{18}\end{array}$} & \multirow{3}{*}{$\begin{array}{l}\text { Alpine grasslands at high eleva- } \\
\text { tions (Andean Puna and Páramos), } \\
\text { Montane grasslands at lower eleva- } \\
\text { tions (Western Ghats, Campos } \\
\text { Rupestres) }\end{array}$} & Páramos: above $3000 \mathrm{~m}$ asl & \multirow{2}{*}{$\sim 846,286 \mathrm{~km}^{2}$} \\
\hline & & & Puna: above $3400 \mathrm{~m}$ asl ${ }^{18}$ & \\
\hline & & & Campos Rupestres: $900-2000 \mathrm{~m}$ asl & $\begin{array}{l}\text { Sum of all tropical-mountain } \\
\text { grassland types extracted from }\end{array}$ \\
\hline Tree line ecotone & $\begin{array}{l}\text { Transition ecosystem between } \\
\text { tree life forms and graminoids, } \\
\text { forbs or shrubs with a-seasonal } \\
\text { growing patterns and controlled } \\
\text { by temperature and/or land use } \mathrm{e}^{20} \text {. } \\
\text { Can assume different types of } \\
\text { shapes, such as sharp transition, } \\
\text { stunted trees, tree island outposts } \\
\text { or gradual ecotone }{ }^{21}\end{array}$ & $\begin{array}{l}\text { Shrublands, Sub-alpine Polylepis } \\
\text { forest, High Andean Forest }\end{array}$ & $\begin{array}{l}\text { Variable elevations, dependent on } \\
\text { local topographical and climato- } \\
\text { logical positions }\end{array}$ & No estimates available \\
\hline Azonal formations & $\begin{array}{l}\text { Spatially restricted non-zonal } \\
\text { ecosystem that occur due to topo- } \\
\text { graphical or hydrological features }\end{array}$ & $\begin{array}{l}\text { Mountain peatlands and bogs, } \\
\text { Riparian ecosystems, Inselberg } \\
\text { forests }\end{array}$ & Variable elevations & No estimates available \\
\hline $\begin{array}{l}\text { Montane cloud forest (hereafter } \\
\text { 'cloud forest') }\end{array}$ & $\begin{array}{l}\text { Forested ecosystem shaped by } \\
\text { frequent fog immersion, wetness } \\
\text { and windy conditions. Harbours a } \\
\text { distinct tree and epiphyte commu- } \\
\text { nity with functional adaptations to } \\
\text { the mountain hydrology and high } \\
\text { elevation conditions }\end{array}$ & $\begin{array}{l}\text { Lower montane cloud forest, } \\
\text { Upper montane cloud forest, Sub- } \\
\text { alpine cloud forest/'Elfin' forest }\end{array}$ & $\begin{array}{l}\text { Generally, between } 1200-1500 \mathrm{~m} \\
\text { asl. But lower boundary of } \\
400 \text { masl on some islands-and } \\
\text { of } 2000 \mathrm{~m} \text { asl on large mountain } \\
\text { ranges }^{22}\end{array}$ & $\begin{array}{l}\sim 214,630 \mathrm{~km}^{222} \text { (i.e. } 6 \% \text { of all } \\
\text { montane tropical forests) }\end{array}$ \\
\hline \multirow{3}{*}{ Montane forest } & \multirow{3}{*}{$\begin{array}{l}\text { Elevation forest with colder } \\
\text { temperatures and distinct abiotic } \\
\text { conditions to lowland forests. } \\
\text { Forests usually show higher stem } \\
\text { density, lower DBH, stem length } \\
\text { and leaf area index with increasing } \\
\text { elevation }{ }^{23}\end{array}$} & \multirow{3}{*}{$\begin{array}{l}\text { Lower montane forest, upper } \\
\text { montane forest, dry montane for- } \\
\text { est, wet montane forest, montane } \\
\text { bamboo forest }\end{array}$} & $500-3500 \mathrm{~m}$ asl & \multirow{3}{*}{$3,257,275 \mathrm{~km}^{222}$} \\
\hline & & & $\begin{array}{l}\text { Montane forests sensu Strictu } \\
1000-3500 \mathrm{~m} \text { asl }\end{array}$ & \\
\hline & & & $\begin{array}{l}\text { Pre-montane forests } 500-1000 \mathrm{~m} \\
\text { asl }\end{array}$ & \\
\hline
\end{tabular}

Table 1. Definition and description of the five tropical mountain ecosystems, their ecological features and the total area in the tropics.

storage or adaptation), and providing ecosystem services (such as water regulation or food provision) for cultural and spiritual reasons ${ }^{30}$. While restoration is by no means a replacement for protection of intact ecosystems, it is a useful complementary conservation strategy to recover degraded land, such as in the case of reforestation ${ }^{27}$.

Thus far, tropical ecosystem restoration has pre-dominantly been focussed around the lowlands, where restoration ecology has been thoroughly studied and synthesized in recent years ${ }^{31-34}$ and various restoration methods have been tested and compared ${ }^{34}$. On the other hand, only a handful of reviews have addressed restoration questions related to TME, most of which are specific to a single tropical mountain ecosystem type or to a specific restoration context $\mathrm{t}^{31-33,35-39}$.

To the best of our knowledge there is no pantropical synthesis of scientific knowledge on ecosystem restoration in tropical mountain ecosystems. By completing a systematic review of 980 search entries and a meta-analysis of 176 systematically selected TME restoration studies following the SALSA methodology ${ }^{40}$ (see "Methods"), we address four key questions: (1) When, where, how and why does tropical mountain restoration research take place? (2) What restoration methods are used in TME restoration? (3) What limits or promotes success in TME restoration? We then discuss these questions in the light of climate change in tropical mountains and present research directions for TME restoration research for the upcoming UN Decade of Restoration.

\section{The state of science in tropical mountain restoration}

Tropical mountain restoration research reveals strong geographical and research nodes. Most TME restoration studies came from study locations in Central and South America (67\%, Fig. 1a). Mexico was the most represented country with $18 \%$ of all studies, followed by Colombia (13\%) and Costa Rica (9.3\%).

Half of the Latin American studies took place outside the large mountain range of the Andes, particularly in small Central American mountain ranges such as the Talamanca Mountains (Costa Rica) and Sierra Madre Oriental (Mexico). This Central American focus mirrors the common trend in tropical ecology, where most science continues to come from a few concentrated research locations.

TME restoration studies in Africa were scarce (only $9 \%$ of studies, Fig. 1b), despite the occurrence of prominent mountain ranges such as the Ethiopian and Cameroon Highlands, Tanzanian Eastern Arc mountains, or Mt. Kilimanjaro. Similarly, few studies were conducted in Asian tropical mountains (5\% South Asia and 8\% in South-East Asia), despite the existence of extraordinarily biodiverse and highly threatened mountain ecosystems such as montane grasslands in the Western Ghats ${ }^{41,42}$.

For Mexican TME studies, 97\% of first authors came from Mexican institutions. For Costa Rican TME research, 2/3 of funding and authors came from US based institutions (Supplementary Fig. 1). Funding for Colombian restoration studies was split between Colombian institutions (40\%), Global North countries (US, Norway, Germany, UK, together 47\%) and supra-national institutions (United Nations, European Union, together 9\%). 


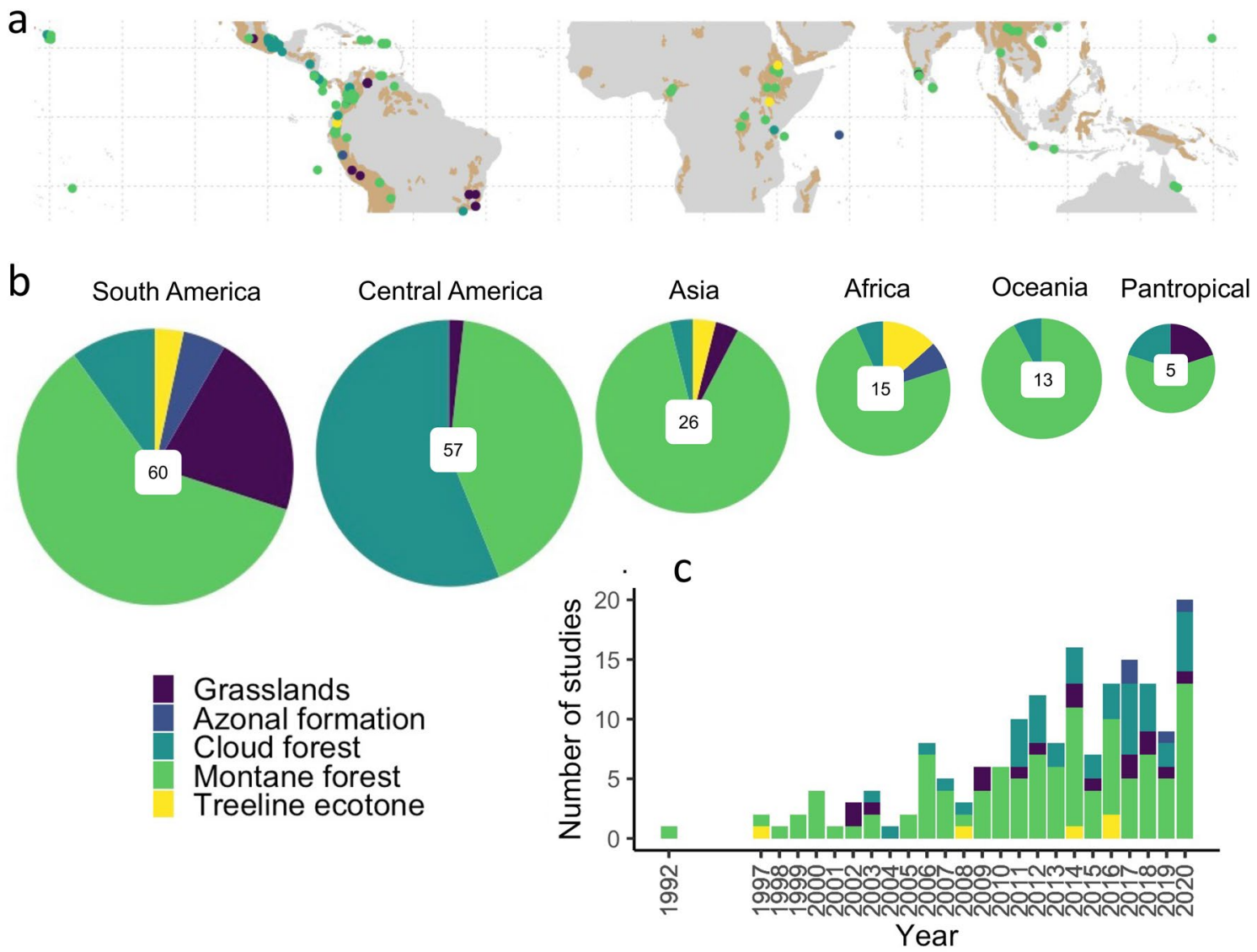

Figure 1. Steady increase in TME studies since the 1990s with a focus on Latin-America and forested mountain ecosystems. (a) Location of studies in the different mountain ecosystems in relation to the tropical mountain ranges. Mountain shapefile data from Global Mountain Biodiversity Assessment ${ }^{43}$, base map from R package 'maptools' ${ }^{44}$ http://CRAN.R-project.org/package=maptools). (b) Ecosystem type pie charts for each geographic region scaled in descending order of total number of studies (number in middle of each pie chart). Pantropical refers to studies carried out in multiple geographic regions, c) Number of studies over time for each ecosystem. All figures were generated in R studio version 3.6.2 $2^{45}$ and using the package 'ggplot2'46.

The number of TME restoration studies remained very low until 2005, followed by a steady increase, reaching maximum numbers in 2020 at the onset of the start of the UN decade of restoration (Fig. 1c). Restoration studies in montane forests were predominant throughout, and almost the only ones before 2000. Since 2004 studies in cloud forests and mountain grasslands increased, while studies about the treeline and azonal formations remained anecdotal through the entire period.

Strong focus on montane and cloud forests. From an ecosystem perspective, we found a strong focus on forested ecosystems with $62 \%$ of studies looking at montane forests, $24 \%$ of the studies focusing on cloud forests, $9 \%$ on grasslands and even smaller percentages for other azonal ecosystems (Fig. 1b). While this can be explained by the fact that forested tropical mountain ecosystems comprise more than four times the area of mountain grasslands $\left(\sim 3,500,000 \mathrm{~km}^{2}\right.$ vs $846,286 \mathrm{~km}^{2}$, see Table 1$)$, the flipside of this 'forest focus' is a scarcity of restoration studies in montane and alpine grasslands, many of which rank among the most biodiverse and endemic ecosystems in the world ${ }^{18,47-49}$.

The current focus on reforestation and tree planting in the international restoration agenda ${ }^{27,50}$, exemplified by large international tree planting commitments such as Trillion Trees ${ }^{51}$ and the Bonn Challenge ${ }^{28}$, could also contribute to this dominance of forest restoration studies. Less than a dozen studies were carried out in the vast expanses of the Páramos and Puna ${ }^{52-58}$ and a few studies in the Brazilian Campos Rupestres ${ }^{48,59,60}$ and Western Ghats ${ }^{41,42,61}$. We found only 5 studies $(2.8 \%)$ on restoration in the tree line ecotone ${ }^{6,37,62-64}$.

We found theme-specific geographic hotspots, such as Veracruz (Mexico) for studies on cloud forest recovery and restoration in abandoned pastures ${ }^{65-70}$. In Hawaii, Mauna Kea was a hotspot for restoration research in montane forest around management of invasive feral pigs ${ }^{9,71-76}$. Finally, eastern Africa was a hotspot around agroforestry and productivity restoration on cultivated mountain slopes ${ }^{6,77-79}$.

Bias towards short temporal and small spatial study scales. We characterized studies based on the time scale they look at (short $<1$ year, medium 1-5 year, long $>5$ years) and the spatial scale of the restoration project (patch scale $<10 \mathrm{~km}^{2}$, local scale $10-100 \mathrm{~km}^{2}$, regional scale $100-10,0000 \mathrm{~km}^{2}$ ). Most TME restoration 


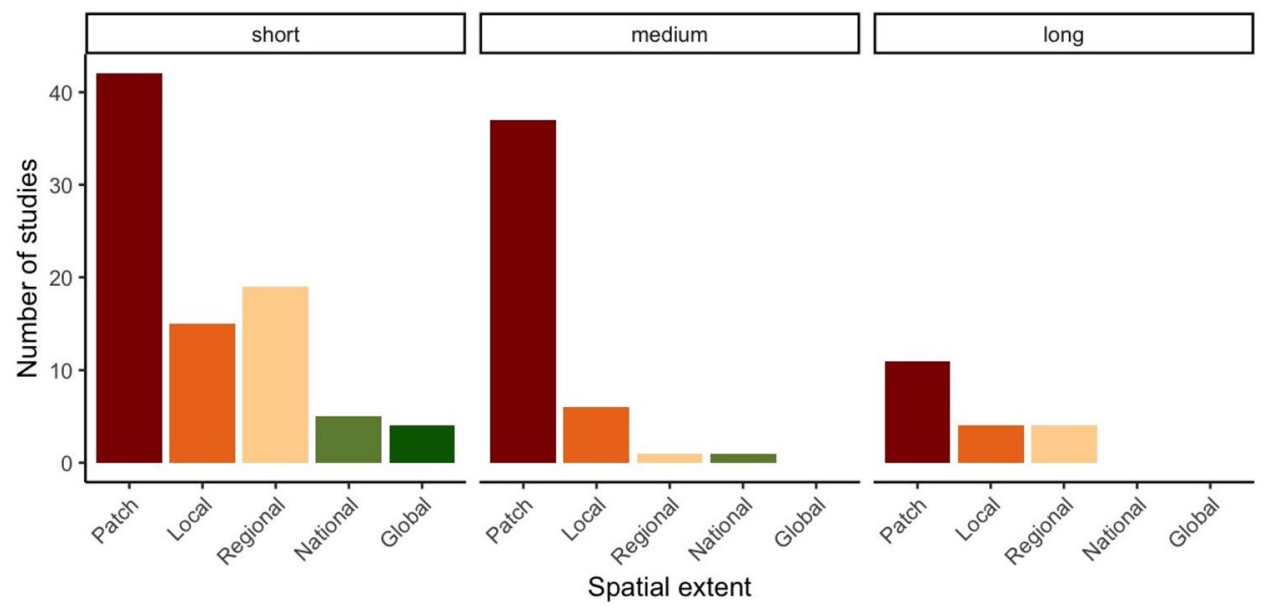

Figure 2. Most TME studies are largely conducted on small spatial scales and in the short term. Spatial categories are: Patch: $10-10^{2} \mathrm{~km}^{2}$, Local: $10^{2}-10^{3} \mathrm{~km}^{2}$, Regional: $10^{3}-10^{5} \mathrm{~km}^{2}$, National: $10^{5}-10^{6} \mathrm{~km}^{2}$, Global: $>10^{6} \mathrm{~km}^{2}$. Temporal categories are short term $<1$ year, medium term $=1-5$ years, long-term: $>5$ years. Figure generated in R studio version 3.6.2 $2^{45}$ and using the package 'ggplot ${ }^{\prime 46}$.

studies were short in time and small in space (Fig. 2). Most of the studies (57\%) were conducted in the shortterm and in the mid-term (30\%). Only $13 \%$ of studies were long-term with only six studies lasting more than 20 years $^{6,80-84}$, all of which were in cloud or montane forest. Over $33 \%$ of the studies were on a patch scale followed by local-scale studies and regional scale studies. There were only 5 pantropical/global assessments, which drew comparisons of restoration processes across distant mountain ranges or across continents ${ }^{38,85-88}$.

These findings are in line with trends in tropical forest restoration, where "neither the scale of scientific studies nor the restoration projects being implemented have matched the ambitious forest landscape restoration plans that are being proposed"89. The small spatial scales, often at the stand level, show that TME restoration science is so far a patchy-small scale endeavour.

While most studies were primary research including fieldwork, secondary research made up less than $15 \%$ of all studies, mostly as reviews ${ }^{86,90-92}$, reports ${ }^{93,94}$, model studies ${ }^{88,95,96}$ and as five remote sensing studies ${ }^{6,61,81,97,98}$.

Dominance of ecological goals and metrics. Most of the reviewed restoration studies had an ecological focus, with over $83 \%$ of studies addressing ecological goals and research questions. Most restoration studies aimed to recover supporting ecosystem services, with forest structure recovery being the most frequent goal, followed by recovery of a species or a combination of species (i.e., biodiversity recovery) and soil recovery (Fig. 3). Regulating ecosystem services, especially water and erosion regulation were targeted due to the importance of mountain areas in providing and regulating the hydrological cycle ${ }^{99,100}$. Plant community variables such as plant species diversity, vegetation structure and plant recruitment were the most frequently studied (Supplementary Fig. 2a,c) ${ }^{87,101-104}$.

Over $39 \%$ of the studies assessed a combination of biotic and abiotic variables or a combination of vegetation and faunal components and as such took a more holistic 'ecosystem approach' (Supplementary Fig. 2b) ${ }^{105-109}$, and $14 \%$ of studies assessed animals as part of restoration efforts (Supplementary Fig. 2c), such as bird communities ${ }^{88,110-112}$ or arthropods ${ }^{113-116}$.

While many studies assessed compositional variables (such as species richness, diversity and composition of vegetation structure) the study of functional traits and functional diversity was comparatively underrepresented. In highly diverse ecosystems the inclusion of functional ecology in restoration assessments, such as through measurements of functional diversity, has been shown to better predict restoration success and trajectories than vegetation composition ${ }^{117}$. Incorporating functional trait assessments in restoration research might be especially relevant in tropical mountain ecosystems, due to the strong influence of climate change and the need of species to migrate upslope to track temperatures ${ }^{118,119}$. For example, in a Nigerian montane forest dispersal mode and seed traits of the forest source population played a large role for the colonization of adjacent naturally regenerating pastures, with small animal-dispersed red seeds being dispersed more often and the furthest ${ }^{120}$. Hence, to passively restore degraded forest, the functional-trait composition of adjacent parent populations should be studied to determine colonization potential.

Only two studies aimed at restoring cultural ecosystem services and only few studies involved communities or looked at socio-economic variables. This neglect of socio-ecological dimensions is in line the current underrepresentation of social outcomes and economic cost calculations in restoration of other tropical ecosystems ${ }^{121}$. The international principles and standards for ecological restoration by the Society for Ecological Restoration ${ }^{122}$ highlight that restoration needs to 'effectively engage a range of stakeholders, and fully utilize available scientific, traditional, and local knowledge', as the integration of diverse types of knowledge helps improve ecological, social, and cultural restoration goals. Local and traditional ecological knowledge can aid with species selection, identification of successional trajectories and species interactions, as well as the right choice of management strategies 


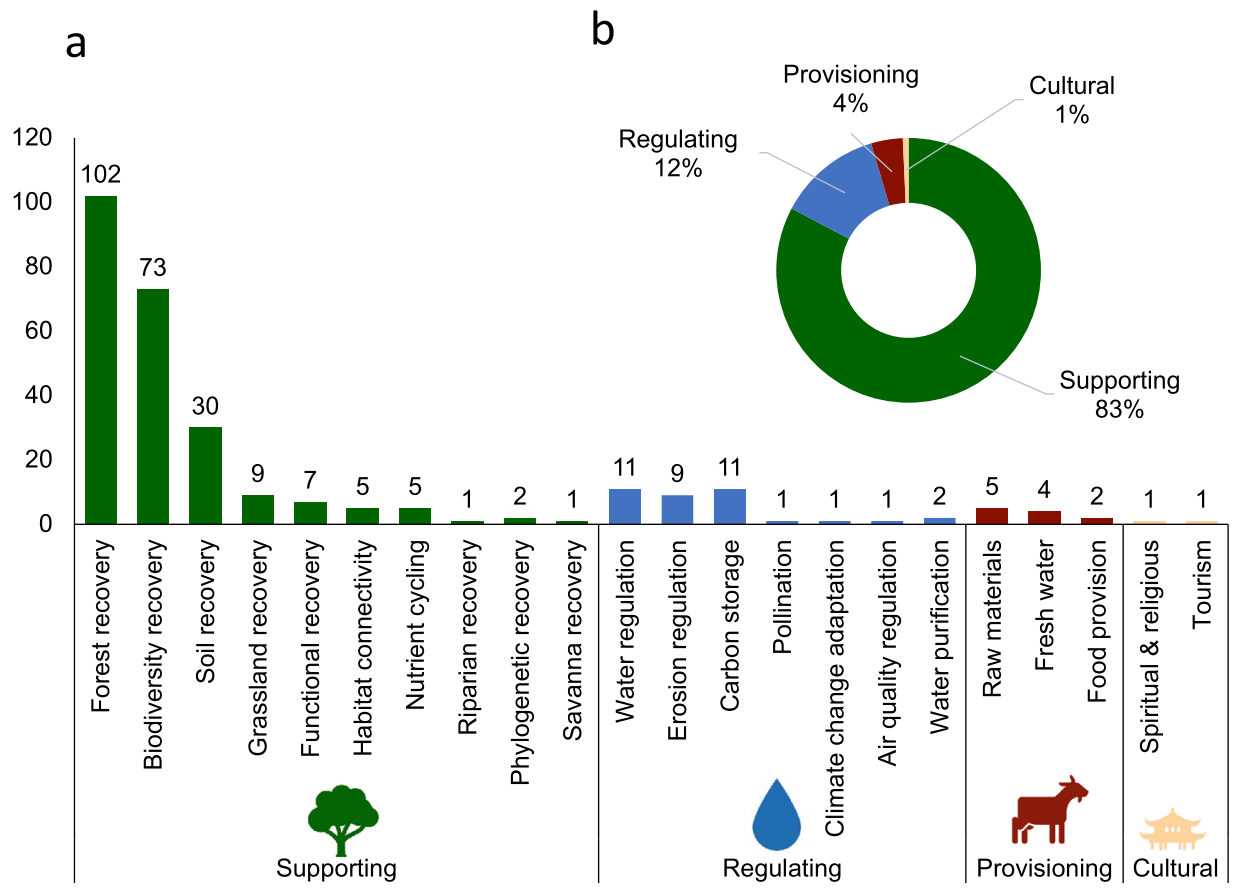

Figure 3. Dominance of supporting ecosystem services as restoration goals. Goals (ecosystem services) and objectives (measurable targets) of restoration studies (A) number of objectives for each ecosystem service goal (B) grouped into the four ecosystem service goals. Figure generated in Excel.

involving cultural practices from prescribed burns to grazing management ${ }^{122}$. Some reviewed studies made use of local ecological knowledge by consulting local communities about values and preferences for tree species ${ }^{123}$ or about land use legacy and age of study sites ${ }^{6,112,124,125}$. Only a few studies included economic calculations to estimate cost and/or revenue from timber of restoration plantings ${ }^{71,88,126,127}$.

Initial degradation due to agriculture and pasture use. Across all TME initial ecosystems degradation occurred mostly due to agricultural conversion and cultivation (53\% of all studies), pasture use (51\%) or deforestation and degradation (e.g., logging, clearing, selective logging etc., 46\%) (Fig. 4). Plantation use, fire and natural hazards played a substantial role in degradation, too (10-19\% of studies). In most studies initial degradation resulted from a combination of multiple degradation causes.

Initial degradation is however site-specific and result in intricate ecological effects posing barriers to restoration, ranging from faunal and vegetation changes, to modified soil and hydrology (Supplementary Figs. 3 and $4 \mathrm{~b}$ ). Arrested succession, i.e., an ecosystem being halted in an early successional state, was a prominent effect of degradation addressed across TMEs ${ }^{56,62,105}$. Reductions in species, functional or genetic diversity or vegetation changes or reductions in vegetation cover or structure were a direct result of initial degradation and particularly prevalent in the highly threatened cloud forests and in montane forests ${ }^{105,107,128-130}$.

Natural regeneration and seedling planting dominate restoration interventions across TME. Across all TME, natural regeneration was the intervention most frequently studied (43\% of all studies), followed by seedling planting (25\%) and invasive plant management (18\%) (Fig. 5 and Supplementary Fig. 5) and often a combination of multiple restoration interventions was investigated.

Seedling planting was mainly deployed in cloud forest and montane forest (Fig. 5), mostly using a few plant families (Supplementary Fig. 5b): Fabaceae to enrich the soil with nitrogen, Myrtaceae (especially Eucalypts) because of fast growth traits and suitability for plantation growth ${ }^{8}$ and Fagaceae because of their high conservation value in Costa Rica and Mexico ${ }^{131-134} .75 \%$ of active restoration studies used exclusively native plant material, $17 \%$ used non-native material and $8 \%$ studied a mix of native and non-native plants (Supplementary Fig. 6a). Non-native plants were introduced due to easy acquisition, economic viability, fast growth, and facilitative effects for native forest recovery ${ }^{135}$. In $44 \%$ of active restoration studies restoration vegetation was animal dispersed, and in 34\% wind dispersed (Supplementary Fig. 6b).

Plantations were used as a restoration intervention in cloud and montane forests, with exotic plantations frequently studied in montane forest (Fig. 5). Direct seeding of species and enrichment planting was most frequently studied in montane forest. A host of additional experimental methods were tested only a few times in the TME restoration studies, such as topsoil, seed bank and hay transfers in the mountain grasslands of the Campos Rupestres ${ }^{48,108}$, applied nucleation, assisted migration ${ }^{136,137}$ and inoculation of cloud forest seedlings with arbuscular mycorrhizal ${ }^{38,138}$ (Supplementary Fig. 6a). 


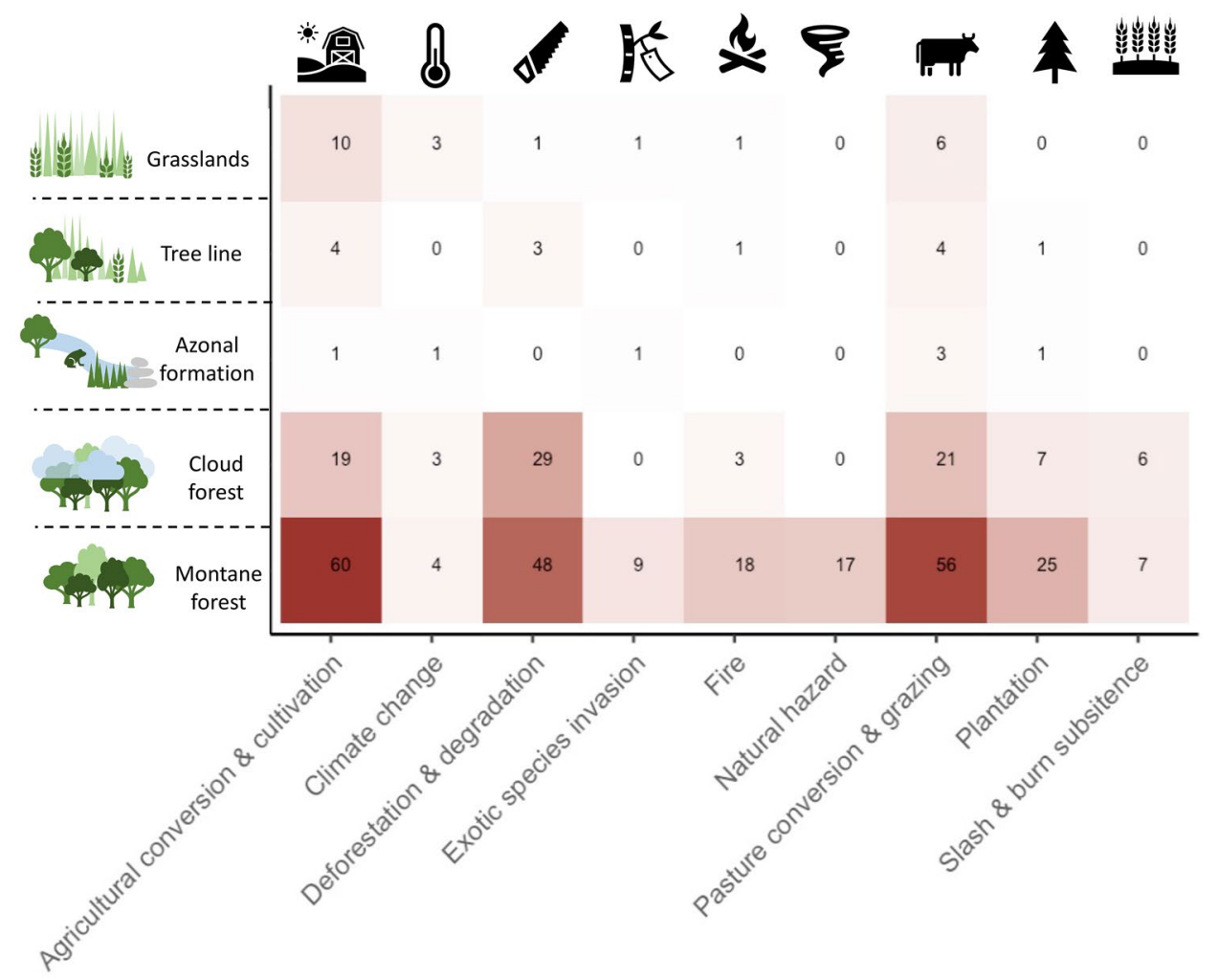

Figure 4. Agriculture, pasture conversion and deforestation are main drivers of initial degradation across TME. Displayed are selected driver of degradation (mentioned more than 10 times across ecosystems) in each TME (for all drivers of degradation see Supplementary Fig. 4a, analogous plot for effects of degradation can be found in Supplementary Figs. 3 and 4b). Figure generated in R studio version 3.6.2 ${ }^{45}$ and using the package 'ggplot2'46.

Active and passive restoration in mountain forests following agricultural degradation. In cloud forests, deforestation, pasture use and live-stock grazing caused harsh abiotic conditions following land abandonment and competition by exotic pasture grasses hindered vegetation recovery ${ }^{76,124,139,140}$. Natural regeneration was the restoration method most often studied in these ecosystems, followed by seedling planting and invasive management.

In montane forests, livestock farming and agriculture create forest-pasture mosaics where forest recovery is limited by seed dispersal, competition with exotic pasture grasses, seed predation and herbivory, and unfavourable site conditions ${ }^{141}$. This required active restoration interventions through tree or shrub seedling planting ${ }^{141}$, nucleation planting ${ }^{11}$ or establishment of perching structures for seed dispersing birds ${ }^{142-144}$ to jointly overcome biotic and abiotic limitations ${ }^{141}$. When natural hazards like hurricanes or landslides ${ }^{145}$ caused soil erosion, restoration in montane forests was focussed on recovering regulating ecosystem functions, such as erosion regulation, water provision and hazard prevention through catchment management ${ }^{135}$, restoration of vegetation cover through revegetation and afforestation ${ }^{101,135}$ and natural regeneration ${ }^{146}$. In montane forests of Hawaiian Acacia invasive species, especially feral ungulates caused degradation. Hence, restoration interventions aimed at recovering native biodiversity through a mixture of invasive control, fencing and landscape zonation ${ }^{72,75,147}$.

In TMEs at lower, more accessible and inhabited elevations, restoration often involved land-sharing approaches such as integrative agroforestry practices, through creation of live hedges and fences on working lands $\mathrm{s}^{78,148}$, underplanting of seedlings in cardamom plantations ${ }^{149}$ or on-farm tree planting to improve ecosystem service provision ${ }^{150}$. On the other hand, in ecosystems less favourable for human inhabitation, land sparing approaches to restoration seemed more common, for instance natural regeneration of cloud forests in pastures $^{115,151-153}$.

Intense active restoration in grassland following strong land use legacies. Agricultural conversion most prominently caused initial degradation in mountain grasslands (Fig. 4), followed by pasture conversion for alpacas and/or cattle, quarrying and mining, and climate change (see Supplementary Fig. 4a with all degradation drivers). This resulted in strong biodiversity and vegetation change, soil and hydrological constraints (Supplementary Fig. 4b).

Commonly, an intense land use legacy reduced restoration success in mountain grasslands-there seemed to be a disturbance threshold beyond which the damage caused by the disturbance was irreversible, mostly related to the soil being too disturbed for native vegetation to recover ${ }^{52,154}$ or due to low seed dispersal ${ }^{48,108}$. 


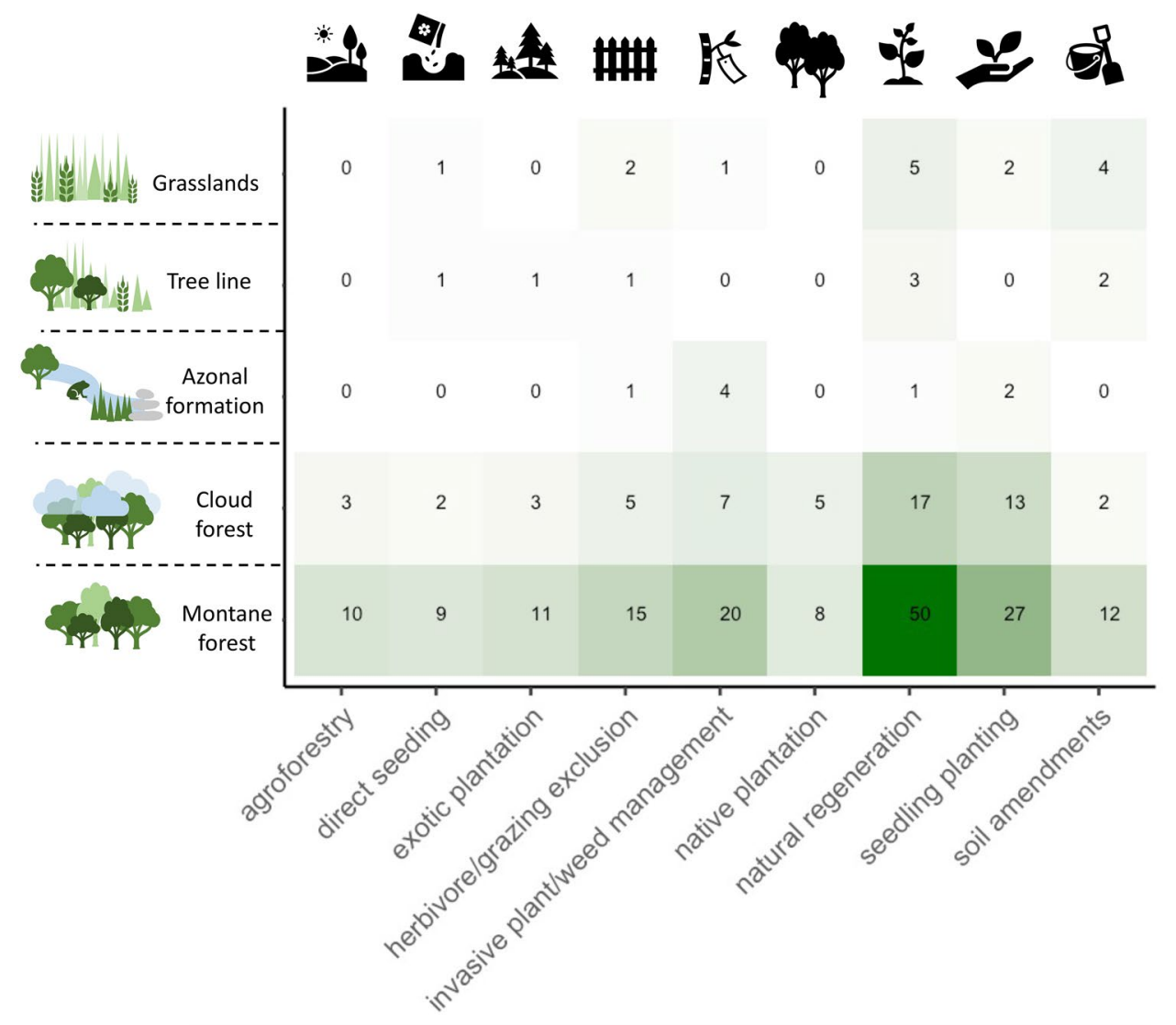

Figure 5. Across TMEs natural regeneration is the most studied restoration intervention, followed by seedling planting and invasive management. Displayed are selected restoration interventions in the tropical mountain ecosystems (mentioned more than 10 times across all ecosystems, see Supplementary Fig. $5 \mathrm{a}$ for all restoration methods). Figure generated in R studio version 3.6.245 and using the package 'ggplot 2 '46.

Natural recovery was generally poor in mountain grasslands, and more intrusive active restoration interventions were needed to restore ecological functions following degradation, such as soil amendments or species introductions. In the Páramos centuries of fallow agriculture coupled with overgrazing left the soils depleted and low in nutrients. Soil organic matter and fertility were restored through necro mass incorporation, manure fertilization and transplantations of mats of nurse plants to provide seed sources and improve soil quality ${ }^{56}$. Likewise, in the Brazilian Campos Rupestres, quarrying and mining led to soil and vegetation losses and species invasion, hindering natural regeneration and demanding more intense restoration methods ${ }^{48,108}$. However, even hay or topsoil transfer still proved unsuccessful in restoring the native grassland communities ${ }^{48,108}$. Similarly, intense restoration methods were trialled and recommended to restore ancient grasslands in the Western Ghats, which suffered species extinction and habitat loss following tree invasion from exotic forestry plantations ${ }^{41,61,155}$. For this purpose Arasumani et al. ${ }^{61}$ used remote sensing to assign priority areas for restoration and invasive tree removal. Their study was the only mountain-grassland restoration study to date that used remote sensing to inform grassland restoration and showcased a promising avenue of using imagery classification for restoration management.

Despite the apparent difficulty to restore mountain grasslands, the knowledge of tropical mountain grassland restoration seems to be at an early stage compared to tropical mountain forest restoration. Further research will be needed to overcome the barriers in mountain grassland restoration, find cost-effective restoration techniques, and create grassland restoration protocols and knowledge databases.

Mixed success of the most studied restoration interventions. We studied restoration success of studies based on how many of the specified objectives (defined in Fig. 3) a restoration intervention achieved (low success $=$ no objectives achieved, medium success $=$ some but not all objectives achieved, high success $=$ almost all/all objectives achieved). Objectives ranged from recovery of biodiversity, soil functions, water and erosion regulation, pollination to food provision and spiritual objectives. The three most prominent restoration interventions across all TME (natural regeneration, seedling planting and plant/weed management) showed mixed levels of success, with most studies classified as 'medium success' (Fig. 6). In cloud and montane forest, more than half of the restoration interventions showed medium success, about $20-30 \%$ high success, and about $10 \%$ low success (Fig. 6a). Studies with low success were particularly frequent in grasslands and the tree line ecotone. 
a

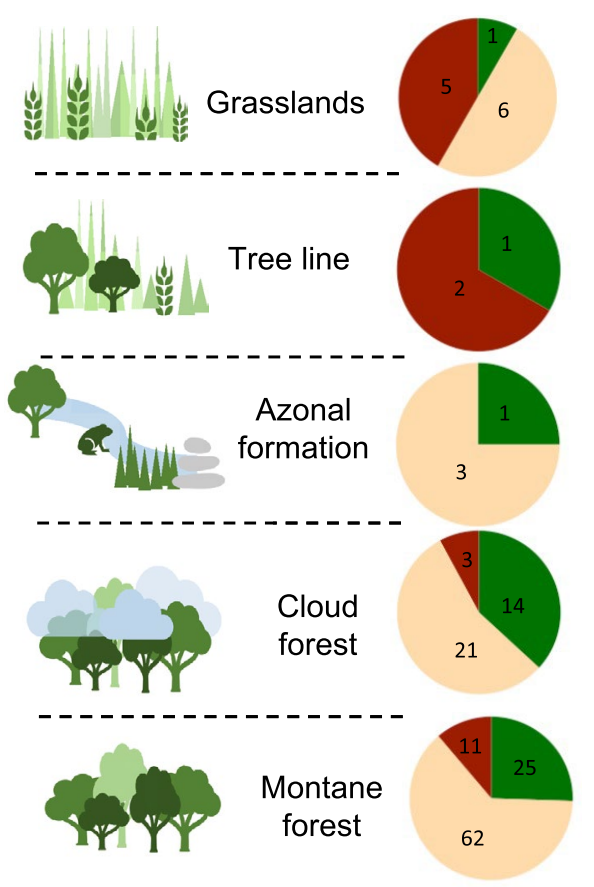

b

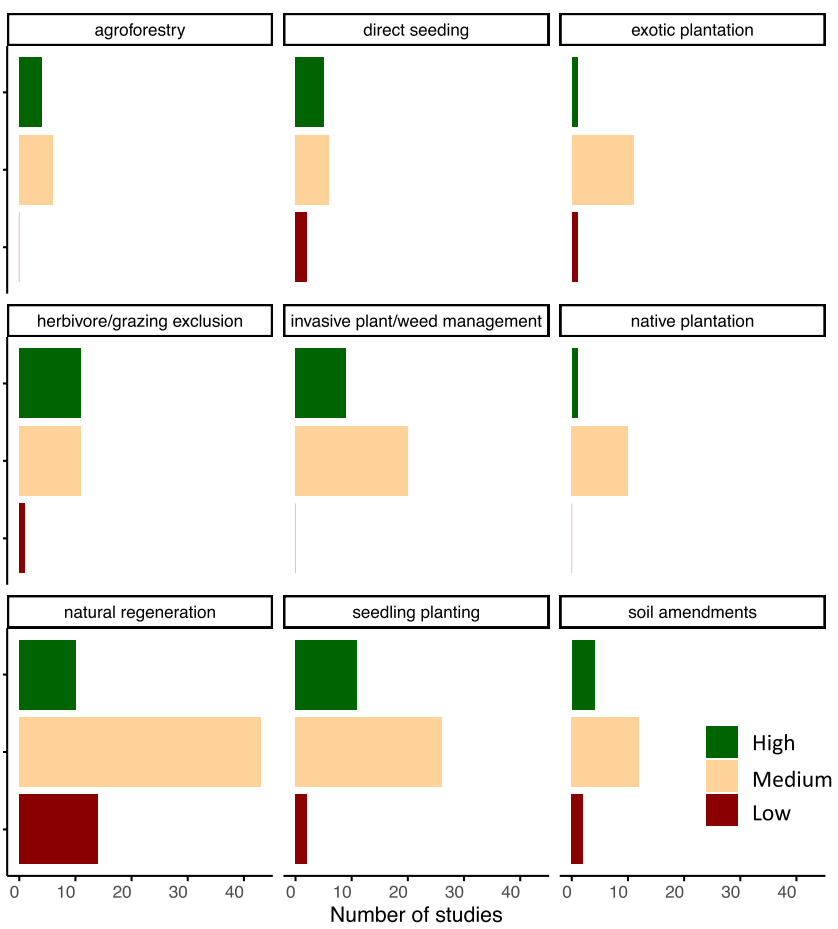

Figure 6. Mixed success rates across restoration interventions. (a) Success rates of restoration in each ecosystem. (b) Success for each of the most prominent restoration interventions (more than 10 times studied) across all ecosystems. All figures generated in R studio version 3.6.2 $2^{45}$ and using the package 'ggplot2 ${ }^{36}$.

Of all restoration methods, strategies removing disturbance (invasive plant management or herbivory/grazing exclusion) showed the highest success. Removing invasive feral pigs from Hawaiian montane forest for instance, improved soil conditions and nutrient regeneration and led to large increases in understory vegetation ${ }^{9}$. In Sri Lankan montane forests a mixture of invasive grass removal, creation of fire breaks, protection of individual trees and isolation of seedling root systems from competitors proved to be successful ${ }^{156}$, showcasing that often multiple strategies removing disturbance need to be combined.

Strategies involving planting or seeding had mixed results and a trend towards medium success (Fig. 6b). For instance, in Mexico mid-to-late successional cloud forest Oak seedlings were transplanted into abandoned pastures and species showed survival rates between 50 to $70 \%$ and due to lower radiative stress resulting from the prevailing cloud cover ${ }^{131}$. Planting has been concluded to be a good option to restore forest and soil quality, however its success depends highly on land-use intensity, initial soil characteristics and species choice ${ }^{157}$.

Agroforestry interventions such as planting of pasture trees or living hedges showed relatively high success levels ( $\sim 40 \%$ high success, $60 \%$ medium) and often succeeded in reaching combined goals of reducing erosion, enhancing water quality ${ }^{78}$ and improving soil conditions for natural regeneration ${ }^{143}$. Plantations, whether exotic or native, showed mostly medium success. Natural regeneration showed mixed results throughout, and its success was strongly dependent on the local site conditions, on proximity to forest for seed rain and on surrounding and remnant vegetation ${ }^{34,158,159}$.

Extensively used TME, such as selectively logged or mixed-plantation systems recovered biodiversity and vegetation structure well under natural regeneration ${ }^{160,161}$. Abandoned agricultural land recovered more slowly due to habitat constraints, dispersal limitations or competition, and often assisted restoration interventions through weeding, direct seeding or fertilization are needed ${ }^{57,162,163}$. In heavily disturbed systems such as pastures invaded by exotic grasses, environmental filtering was strong and restoration success was low without active interventions such as seedling planting ${ }^{164}$ systematic planting or soil/seed bank transfers ${ }^{11}$.

Our review showed that active restoration planting generally did not help reach restoration goals more successfully than natural regeneration and a site-specific approach based on landscape and micro-site attributes will be needed in TME to choose adequate restoration interventions, as previously shown for lowland tropical forests $^{34}$. Deciding on an optimal site specific approach requires identifying the local abiotic and biotic habitat factors constraints recovery and weighing off costs and benefits of different restoration interventions in the light of finance, time and labour constraints ${ }^{163}$.

Seed dispersal and habitat constraints limit restoration success. Restoration success was mostly limited by abiotic habitat constraints and seed dispersal (Fig. 7). Habitat constraints arised as a result of the harsh mountain environments, with low air temperatures and daily temperature amplitudes that often exceeded 


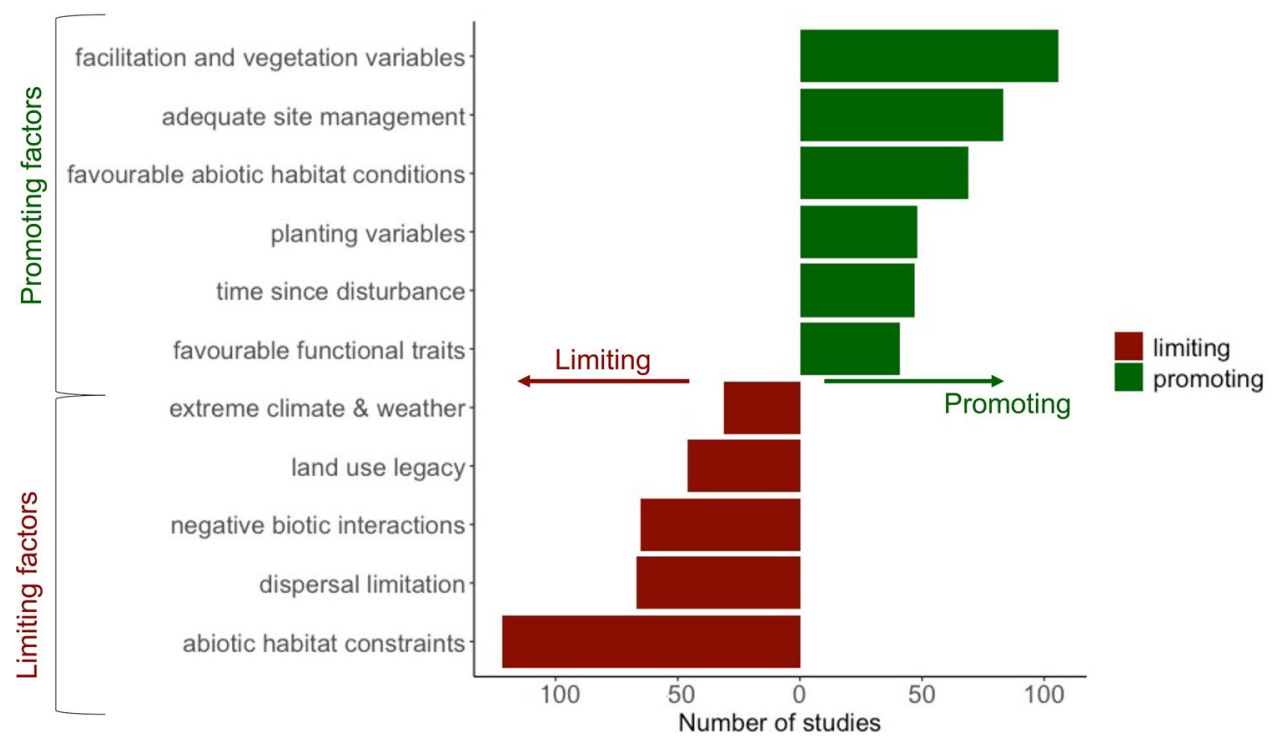

Figure 7. Habitat and dispersal constraints limit restoration success. Factors limiting and promoting restoration success (mentioned more than 30 times across all ecosystems). Factors are arranged on a negative side of the axis if limiting (red), and positive if promoting (green) restoration success (see Supplementary Fig. 7a,b for bar plots of all limiting and promoting factors in each ecosystem). Breakdown of the top three limiting factors: Abiotic habitat constraints encompasses nutrient, water, light and micro-climate limitation, germination, and recruitment limitation. Dispersal limitation encompasses distance from seed source, lack of dispersers, migration limitation. Negative biotic limitations encompass competitive interaction, seed predation, herbivory, pest and disease. Breakdown of the top three promoting factors: facilitation and vegetation variables include structural complexity, proximity to reference habitat, connectivity, remnant vegetation, intra- and interspecific facilitation. Adequate site management includes invasive removal and control, herbivory control, agricultural management, disturbance removal, site protection etc. Favourable abiotic habitat conditions includes beneficial micro-climate, soil conditions, litter properties, light and water availability etc. (see Supplementary Table 3 for all categories). Figure generated in R studio version 3.6.2 ${ }^{45}$ and using the package 'ggplot 2 '46.

seasonal and annual variation ${ }^{63,79}$, recurring frosts ${ }^{165}$, as well as erosion processes due to strong rains, winds, and landslides ${ }^{78,166}$. These factors, in combination with a naturally rugged topography, contributed to acute losses of vegetation, shallow soils and depleted soil seed banks, making it difficult for vegetation to establish ${ }^{146,167}$. These factors often resulted in recruitment limitation ${ }^{8,87,168-170}$.

Limitations due to seed dispersal — the most common form of seed dispersion in TMEs ${ }^{159,171}$ — were exacerbated by habitat loss, fragmentation and degradation which disrupt seed dispersers' abundances and movement pathways ${ }^{65,83,136,172,173}$. Further, negative biotic interactions such as competition between grasses and ferns, pests and diseases, as well as herbivory and seed predation compromised restoration success.

The top promoting factors for restoration success were facilitation and vegetation composition and structure that promotes plant establishment and growth, for instance structural complexity of vegetation, remnant vegetation and proximity to natural habitat. As part of this many studies specifically mentioned facilitation processes which ameliorate micro-environmental site conditions and often contributed to increased restoration success ${ }^{54,104,174,175}$. Facilitative interactions were deliberately employed in restoration studies, e.g. through applied nucleation tree island planting ${ }^{11,172}$, exotic plantations to recover native understories ${ }^{129}$, bracken ferns as facilitators for late succession tree seedlings ${ }^{128}$ or planting to attract seed dispersers ${ }^{120,140,141,172}$. Moreover, site management variables related to removing disturbance, such as eradication of invasive species ${ }^{84,176}$, and protection of restoration sites ${ }^{6,177}$ were mentioned as promoting success. Furthermore, planting variables associated with the right choice of local planting methods, ranging from appropriate seed bank transfers ${ }^{11}$, shade tree ${ }^{178}$ and multi-species planting ${ }^{161}$, and direct seeding ${ }^{163}$ helped improve restoration outcomes.

Restoring the distinct nature of TME in the light of climate change. Climate change will irreversibly change the ecology of many of the world's tropical mountains ${ }^{179}$. Mountain ecosystems are projected to undergo 'elevation-dependent warming, a process by which the rate of warming is amplified with elevation ${ }^{180}$, resulting in new climate niches. At the same time, many established species will track temperatures through upslope migration, as observed in the Andes ${ }^{181}$. Climate-related limitations such as habitat and recruitment constraints are already a prevalent limiting factor across many of the reviewed restoration studies and may be exacerbated with progressing climate change and its interaction with land use changes ${ }^{182}$.

This will require designing tailored restoration interventions based on the expected eco-climatic changes for a given TME. However, only four montane forest studies and three cloud forest studies reviewed specifically addressed climate change as an initial degradation factor (Fig. 3). Tropical montane cloud forests, for instance, are expected to experience shifted cloud and precipitation distributions, resulting in tree mortality and altitudinal 
migration $^{183}$. This may require strategies such as assisting species to migrate upslope to track temperatures ${ }^{137,184}$. Many endemic cloud forest tree species have small population sizes, high habitat specificity and low dispersal, due to lack of habitat connectivity, leading to shifted plant-animal interactions due to climate change which will need to be considered under future climate change scenarios ${ }^{137}$. In mountain grasslands, drought is forecasted to intensify, and a functional eco-physiological approach will be needed to design conservation actions ${ }^{118}$.

There are still large research gaps in the context of restoration under climate change, such as assisted migration and germination potentials for a most species and studies on an ecosystem-by-ecosystem basis on climate change implications for TME restoration. Further, the creation of databases with functional traits that are key to climatic tolerance for tropical mountain plant species will help design restoration interventions that leverage facilitative effects and biotic interactions to improve micro-site conditions and provide local refugia.

\section{Future directions for research}

While mountains have long been targeted for conservation due to their unsuitability for agriculture and other forms of anthropogenic use ('High and Far' bias of protected areas ${ }^{185}$ ), the UN Decade of Restoration provides a crucial policy window for large-scale restoration beyond tree planting and for the incorporation of many diverse kinds of ecosystems and restoration approaches.

This synthesis is the first of its kind to show the prevailing trends in geographical and ecosystem bias in tropical mountain restoration research, highlighting pre-dominant research methods and scales, and reviewing restoration interventions and limiting and enabling factors for restoration success. However, we found large gaps in tropical mountain restoration research, ranging from underrepresentation of non-forested ecosystems and socio-economic restoration goals to lack of use of technologies and scarcity of research on implementation and financial viability of restoration projects. Hence, we devise five directions for future research.

1. Given the overwhelming amount of TME studies on a patch and local scale identified here, research on large-scale restoration ${ }^{186}$ will be needed to scale up mountain restoration to a landscape level. Geo-spatial technologies, such as remote sensing could aid with this, for instance through restoration potential and opportunity assessments for entire mountain ecosystems. Science-based open data initiative like the newly launched portal RESTOR, pave the path for the application of remote sensing for large scale restoration purposes.

2. Studies on the social dimensions of restoration in tropical mountains are still scarce. Making restoration a socio-ecological endeavour is especially critical in dynamic social contexts ${ }^{187}$, such as tropical mountain ecosystem which currently undergoing rapid land use changes and often shared between human use and restoration (e.g. mountain plantations, pastures, and fallow cultivation). Hence, solving questions on land tenure, land abandonment, local preferences, and valued ecosystem services through local participation and partnerships will be key to restoring tropical mountain biodiversity in the long term.

3. Monitoring efforts are a key aspect of the UN decade on restoration ${ }^{188}$. Advancing and applying technologies and monitoring protocols for tropical mountain restoration could help with increasing restoration success for instance through adaptive management. With most reviewed studies conducted in the short-term, longterm restoration trajectories in almost all ecosystems are uncertain. Drone technologies for instance, could provide exciting avenues for recurring monitoring of recovery of vegetation variables on a patch level in inaccessible and remote mountain areas, while also offering opportunities for assisted regeneration via aerial seeding ${ }^{189}$.

4. Thus far, tropical mountain restoration studies that explicitly consider the changing climate in mountains, and tailor restoration interventions to a dynamic future reference state are still scarce. The choice of climate resilient species with the right functional traits will be essential for mountain restoration to thrive under a changing climate. For instance creating 'functional trait libraries' of reference ecosystems and understanding traits that underpin resilience in a specific ecosystem context will be useful to guide the selection of species and restoration approaches.

5. The paucity of restoration studies assessing mountain grassland restoration calls for a better inclusion of these underrepresented systems in future research. Despite the critical importance of alpine grassland systems for water regulation, soil maintenance and biodiversity ${ }^{18}$ and their large extent and degradation status there are very few successful restoration studies in alpine grasslands. The creation of alpine grassland restoration networks and restoration protocols could be a solid next step.

We hope this synthesis will help direct research priorities which can contribute to effectively restore tropical mountains in order to help mountain biodiversity flourish, and ensure that communities that depend on their ecosystem services will thrive for decades to come.

\section{Methods}

We followed the SALSA (Search-Appraisal-Synthesis-Analysis) method which includes the steps of (1) Searching for literature; (2) Appraisal to decide which studies are included; (3) Synthesis and (4) Analysis of studies, as this method has been shown to be applicable to assess knowledge trends and gaps in environmental science research ${ }^{40}$. We preferred this method to other established methods such as PRISMA, PICO or BACI, as we review across a wide set of ecosystems, contextual settings, metrics and restoration interventions, and as such decided not to adopt a purely comparative approach ${ }^{40}$. 
Literature search. Documents were searched on the databases Web of Science, Scopus and Science Direct (search date 20/1/2021) and on Google Scholar (search date 3/12/2020). We included papers for the period 1988-2020, as 1988 marks the foundation date of the Society for Ecological Restoration and 2020 marks the last year before the start of the UN decade for Restoration. We included articles written in any language.

We tested different search strings for Title-Abstract-Keyword (TAK) search of varying length and complexity on the four databases, with the goal of finding a search term that returned a high but manageable number of search hits and enabled high relevance of papers for answering the questions of the review (Supplementary Table 1). We decided on a simple search string that could be applied across all databases despite the different search algorithms. Our final search string across all databases included a word related to restoration (restor ${ }^{\star}$ ), to tropics (tropic ${ }^{*}$ ) and to mountain environments (mountain OR montane OR altitude OR alpine OR andes) (detailed search string specification in Supplementary Table 1), but no word related to specific TME because the nomenclature across TME is not standardized. We decided to include the word 'Andes' as it is often used instead of another mountain-related word. We further did a top up search in Google Scholar in order to include articles in other languages and from smaller national literature databases that might have been missed otherwise (such as Scielo). However, since Google Scholar only allows for full text search as opposed to TAK search, we only included the first 100 search results.

Appraisal: inclusion and exclusion. Our search string yielded a total of 980 articles, of which 532 remained for screening following manual and automated duplicate removal (Supplementary Fig. 8). First, we performed a title and abstract screening to exclude studies that (1) did not have a focus on ecological restoration sensu Society for Ecological Restoration (2002) and (2) were clearly neither in tropical nor mountain locations. We include studies on all kinds of restoration elements and interventions, including passive restoration (e.g. natural regeneration), assisted recovery (e.g. interventions that involve soil amendments, invasive species management etc.) and active restoration (introduction of species, seedling planting, transfer of seed banks etc.). Second, we did a full-text screening of the 245 selected articles to exclude (1) grey literature and (2) studies with locations outside tropical latitudes (i.e. outside $23.5^{\circ} \mathrm{N}$ and $23.5^{\circ} \mathrm{S}$ ) and where study locations were not referred to as montane/mountain/alpine or not situated above $1000 \mathrm{~m}$ asl.

Synthesis and analysis. We synthesized and coded studies using Microsoft Excel, where we extracted tags for the following categories: publication year, study site, study type, initial degradation causes, restoration metrics, restoration methods and success. Each of these categories had additional specific sub-categories. For instance, restoration metrics had the categories: restoration goals; studied response variables; taxonomic groups etc. (Supplementary Table 2). Each study could have multiple tags for each sub-category (e.g. for the restoration goals category each study got assigned as many goals as were mentioned/studied).

For the top three countries with the highest number of TME studies (Mexico, Costa Rica, and Colombia) we extracted first and last author affiliations and country of funding source to elucidate on funding flows and potential bias in geographical authorship.

As a measure of success of restoration interventions, we qualitatively assigned each study the categories low (no/almost no objectives reached), medium (multiple, but not all objectives reached) and high (all/almost all objectives reached), based on how many of its defined objectives were achieved (e.g., a native plantation intended to improve soil, water, vegetation structure and biodiversity but only improved soil qualities and structure would be assigned a medium value). We realize this metric is quite simplistic, but it allowed for general detection of trends across a multitude of different restoration studies that measured different goals, had different research designs and restoration variables of interest. For the same reason, we decided not to study effect sizes, as the study designs, treatments and measured target variables differed too much to give us adequate sample sizes for specific comparison.

Data analysis and visualization was carried out in Excel and in R studio version $1.2 .1335^{45}$ and using the package 'ggplot 2 '46.

\section{Data availability}

The data that support the findings of this study is publicly available on Mendeley Data (https://doi.org/10.17632/ gvy63jydyg.1, URL: https://data.mendeley.com/datasets/gvy63jydyg/1).

Received: 5 October 2021; Accepted: 22 October 2021

Published online: 14 December 2021

\section{References}

1. Dimitrov, D., Nogués-Bravo, D. \& Scharff, N. Why do tropical mountains support exceptionally high biodiversity? The eastern arc mountains and the drivers of saintpaulia diversity. PLoS One 7, e48908 (2012).

2. Spehn, E. \& Körner, C. A Global Assessment of Mountain Biodiversity and its Function, vol. 23, 393-400 (2005).

3. Merckx, V. S. F. T. et al. Evolution of endemism on a young tropical mountain. Nature 524, 347-350 (2015).

4. Mengist, W., Soromessa, T. \& Legese, G. Ecosystem services research in mountainous regions: A systematic literature review on current knowledge and research gaps. Sci. Total Environ. 702, 134581 (2020).

5. Gleeson, E. H. et al. Mountains of our future earth: defining priorities for mountain research: A synthesis from the 2015 Perth III conference. Mt. Res. Dev. 36, 537-548 (2016).

6. Jacob, M. et al. Land use and cover dynamics since 1964 in the Afro-Alpine vegetation belt: Lib Amba Mountain in North Ethiopia. Land Degrad. Dev. 27, 641-653 (2016).

7. Dhakal, B. et al. Impacts of cardamom cultivation on montane forest ecosystems in Sri Lanka. For. Ecol. Manag. 274, 151-160 (2012). 
8. Thijs, K. W. et al. Contrasting cloud forest restoration potential between plantations of different exotic tree species. Restor. Ecol. 22, 472-479 (2014).

9. Long, M. S. et al. Impact of nonnative feral pig removal on soil structure and nutrient availability in Hawaiian tropical montane wet forests. Biol. Invasions 19, 749-763 (2017).

10. Elgar, A. T., Freebody, K., Pohlman, C. L., Shoo, L. P. \& Catterall, C. P. Overcoming barriers to seedling regeneration during forest restoration on tropical pasture land and the potential value of woody weeds. Front. Plant Sci. 5, 200 (2014).

11. Rojas-Botero, S., Solorza-Bejarano, J., Kollmann, J. \& Teixeira, L. H. Nucleation increases understory species and functional diversity in early tropical forest restoration. Ecol. Eng. 158, 106031 (2020).

12. Hooper, E., Legendre, P. \& Condit, R. Barriers to forest regeneration of deforested and abandoned land in Panama. J. Appl. Ecol. 42, 1165-1174 (2005).

13. Krishnaswamy, J., John, R. \& Joseph, S. Consistent response of vegetation dynamics to recent climate change in tropical mountain regions. Glob. Change Biol. 20, 203-215 (2013).

14. Soh, M. C. K. et al. Impacts of habitat degradation on tropical montane biodiversity and ecosystem services: A systematic map for identifying future research priorities. Front. For. Glob. Change 2, 1-18 (2019).

15. Tovar, C., Arnillas, C. A., Cuesta, F. \& Buytaert, W. Diverging responses of tropical andean biomes under future climate conditions. PLoS One 8, e63634 (2013).

16. Helmer, E. H. et al. Neotropical cloud forests and páramo to contract and dry from declines in cloud immersion and frost. PLoS One 14, e0213155 (2019).

17. Hall, J., Burgess, N. D., Lovett, J., Mbilinyi, B. \& Gereau, R. E. Conservation implications of deforestation across an elevational gradient in the Eastern Arc Mountains, Tanzania. Biol. Conserv. 142, 2510-2521 (2009).

18. Christmann, T. \& Oliveras, I. Nature of alpine ecosystems in tropical mountains of South America. in Encyclopedia of the World's Biomes 1-10 (Elsevier Inc., 2020). https://doi.org/10.1016/B978-0-12-409548-9.12481-9

19. Dixon, A. P., Faber-Langendoen, D., Josse, C., Morrison, J. \& Loucks, C. J. Distribution mapping of world grassland types. J. Biogeogr. 41, 2003-2019 (2014).

20. Young, K. R. \& León, B. Tree-line changes along the Andes: Implications of spatial patterns and dynamics. Philos. Trans. R. Soc. B Biol. Sci. 362, 263-272 (2007).

21. Harsch, M. A. \& Bader, M. Y. Treeline form-A potential key to understanding treeline dynamics. Glob. Ecol. Biogeogr. 20, 582-596 (2011).

22. Bruijnzeel, L. A., Mulligan, M. \& Scatena, F. N. Hydrometeorology of tropical montane cloud forests: Emerging patterns. Hydrol. Process. 25, 465-498 (2011).

23. Kessler, M. \& Kluge, J. Diversity and endemism in tropical montane forests-From patterns to processes. Tropical Mountain Forest: Patterns and Processes in a Biodiversity Hotspot, vol. 2 (2010).

24. Aide, T. M. \& Grau, H. R. Globalization, migration, and Latin American ecosystems. Science 305, 1915-1917 (2004).

25. Bender, O. Abandoned altitudes? Decrease and expansion of grassland in the Hinterland of Popayán, Southern Colombian Andes. J. Mt. Sci. 12, 123-133 (2015).

26. Zhang, B., Mo, S., Tan, T., Xiao, F. \& Wu, H. Urbanization and De-urbanization in mountain regions of China. Mt. Res. Dev. 24, 206-209 (2004).

27. Di Sacco, A. et al. Ten golden rules for reforestation to optimize carbon sequestration, biodiversity recovery and livelihood benefits. Glob. Change Biol. https://doi.org/10.1111/gcb.15498 (2021).

28. International Union for Conservation of Nature. The Bonn Challenge | Bonchallenge. Iucn (2020).

29. Society for Ecological Restoration. The SER primer on ecological restoration. Sci. Policy Work. Gr. 2002, 9 (2002).

30. Holl, K. D. Primer of Ecological Restoration (Island Press, 2020). https://doi.org/10.1007/s13412-020-00621-w.

31. Chazdon, R. REVIEW: Restoring tropical forests: A practical guide. Ecol. Restor. 33, 118-119 (2015).

32. Chazdon, R. L. Tropical forest recovery: Legacies of human impact and natural disturbances. Perspect. Plant Ecol. Evol. Syst. 6, 51-71 (2003).

33. Ghazoul, J. \& Chazdon, R. Degradation and recovery in changing forest landscapes: A multiscale conceptual framework. Annu. Rev. Environ. Resour. 42, 161-188 (2017).

34. Meli, P. et al. A global review of past land use, climate, and active vs passive restoration effects on forest recovery. PLoS One 12, 1-17 (2017)

35. Holl, K. D. Restoration of tropical forests. Restor. Ecol. New Front. https://doi.org/10.1002/9781118223130.ch9 (2012).

36. Meli, P. Tropical forest restoration. Twenty years of academic research. Interciencia 28, 581 (2003).

37. Venkatesh, B., Lakshman, N. \& Purandara, B. K. Hydrological impacts of afforestation-A review of research in India. J. For. Res. 25, 37-42 (2014).

38. Aide, T. M., Ruiz-Jaen, M. C. \& Grau, H. R. What is the state of tropical montane cloud forest restoration? Tropical Montane Cloud Forests: science for conservation and management. For. Ecol. Manag. https://doi.org/10.1017/CBO9780511778384.010 (2011).

39. Guariguata, M. R. Restoring tropical montane forests. Forest Restoration in Landscapes: Beyond Planting Trees (2005). https:// doi.org/10.1007/0-387-29112-1_43

40. Mengist, W., Soromessa, T. \& Legese, G. Method for conducting systematic literature review and meta-analysis for environmental science research. MethodsX 7, 100777 (2020).

41. Arasumani, M. et al. Not seeing the grass for the trees: Timber plantations and agriculture shrink tropical montane grassland by two-thirds over four decades in the Palani Hills, a Western Ghats Sky Island. PLoS One 13, e0190003 (2018).

42. Raman, T. R. S., Mudappa, D. \& Kapoor, V. Restoring rainforest fragments: survival of mixed-native species seedlings under contrasting site conditions in the Western Ghats, India. Restor. Ecol. 17, 137-147 (2009).

43. Körner, C. et al. A global inventory of mountains for bio-geographical applications. Alp. Bot. 127, 1-15 (2017)

44. Lewin-Koh, N. J. et al. maptools: Tools for reading and handling spatial objects. R package version 0.8-10. http://CRAN.R-proje ct.org/package=maptools (2011).

45. R Core Team. R: A language and environment for statistical computing (R Foundation for Statistical Computing, 2019). https:// www.R-project.org/

46. Wickham, H. ggplot2: Elegant Graphics for Data Analysis (Springer, 2016). ISBN 978-3-319-24277-4. https://ggplot2.tidyverse. org

47. Srinivasan, M. P., Bhatia, S. \& Shenoy, K. Vegetation-environment relationships in a South Asian tropical montane grassland ecosystem: Restoration implications. Trop. Ecol. 56, 201-217 (2015).

48. Le Stradic, S., Buisson, E. \& Fernandes, G. W. Restoration of Neotropical grasslands degraded by quarrying using hay transfer. Appl. Veg. Sci. 17, 482-492 (2014).

49. De De Vasconcelos, M. F. O que são campos rupestres e campos de altitude nos topos de montanha do Leste do Brasil?. Rev. Bras. Bot. 34, 241-246 (2011).

50. Seddon, N. et al. Getting the message right on nature-based solutions to climate change. Glob. Change Biol. https://doi.org/10. $1111 / \mathrm{gcb} .15513(2021)$.

51. Home | Trillion Trees (2020). 
52. Abadín, J. et al. Successional dynamics of soil characteristics in a long fallow agricultural system of the high tropical Andes. Soil Biol. Biochem. 34, 1739-1748 (2002).

53. Abreu, Z., Llambí, L. D. \& Sarmiento, L. Sensitivity of soil restoration indicators during páramo succession in the high tropical andes: Chronosequence and permanent plot approaches. Restor. Ecol. 17, 619-627 (2009).

54. Bueno, A. \& Llambí, L. D. Facilitation and edge effects influence vegetation regeneration in old-fields at the tropical Andean forest line. Appl. Veg. Sci. 18, 613-623 (2015).

55. Sarmiento, L., Llambí, L. D., Escalona, A. \& Marquez, N. Vegetation patterns, regeneration rates and divergence in an old-field succession of the high tropical Andes. Plant Ecol. 166, 63-74 (2003).

56. Sarmiento, L., Smith, J. K., Márquez, N., Escalona, A. \& Erazo, M. C. Constraints for the restoration of tropical alpine vegetation on degraded slopes of the Venezuelan Andes. Plant Ecol. Divers. 8, 277-291 (2015).

57. Sarmiento, L. \& Bottner, P. Carbon and nitrogen dynamics in two soils with different fallow times in the high tropical Andes: Indications for fertility restoration. Appl. Soil Ecol. 19, 79-89 (2002).

58. Sarmiento, L., Abadín, J., González-Prieto, S. \& Carballas, T. Assessing and modeling the role of the native legume Lupinus meridanus in fertility restoration in a heterogeneous mountain environment of the tropical Andes. Agric. Ecosyst. Environ. 159, 29-39 (2012).

59. Hilário, R. R., Castro, S. A. B., Ker, F. T. O. \& Fernandes, G. Unexpected effects of pigeon-peas (Cajanus cajan) in the restoration of rupestrian fields [Efeito Inesperado do Feijão-Guandu (Cajanus cajan) na Restauração de Campos Rupestres]. Planta Daninha 29, 717-723 (2011).

60. Le Stradic, S., Buisson, E., Negreiros, D., Campagne, P. \& Wilson Fernandes, G. The role of native woody species in the restoration of Campos Rupestres in quarries. Appl. Veg. Sci. 17, 109-120 (2014).

61. Arasumani, M., Bunyan, M. \& Robin, V. V. Opportunities and challenges in using remote sensing for invasive tree species management, and in the identification of restoration sites in tropical montane grasslands. J. Environ. Manag. 280, 111759 (2020).

62. Sarmiento, F. O. Arrested succession in pastures hinders regeneration of Tropandean forests and shreds mountain landscapes. Environ. Conserv. 24, 14-23 (1997).

63. Wesche, K. et al. Recruitment of trees at tropical alpine treelines: Erica in Africa versus Polylepis in South America. Plant Ecol. Divers. 1, 35-46 (2008).

64. Middendorp, R. S., Pérez, A. J., Molina, A., Lambin, E. F. \& Pérez Castañeda, A. J. The potential to restore native woody plant richness and composition in a reforesting landscape: A modeling approach in the Ecuadorian Andes. Landsc. Ecol. 31, 1581-1599 (2016).

65. De Guevara, I.H.-L., Rojas-Soto, O. R., López-Barrera, F., Puebla-Olivares, F. \& Díaz-Castelazo, C. Seed dispersal by birds in a cloud forest landscape in central Veracruz, Mexico: Its role in passive restoration. Rev. Chil. Hist. Nat. 85, 89-100 (2012).

66. Lira-Noriega, A., Guevara, S., Laborde, J. \& Sanchez-Rios, G. Floristic composition in pastures of Los Tuxtlas, Veracruz, Mexico. ACTA Bot. Mex. 80, 59-87 (2007).

67. Muniz-Castro, M. A., Williams-Linera, G. \& Benayas, J. M. R. Distance effect from cloud forest fragments on plant community structure in abandoned pastures in Veracruz, Mexico. J. Trop. Ecol. 22, 431-440 (2006).

68. Räger, N., Williams-Linera, G. \& Huth, A. Modeling the dynamics of tropical montane cloud forest in central Veracruz, Mexico. in Tropical Montane Cloud Forests: Science for Conservation and Management 584-594 (2011). https://doi.org/10.1017/CBO97 80511778384.063

69. Violi, H. A. et al. Disturbance changes arbuscular mycorrhizal fungal phenology and soil glomalin concentrations but not fungal spore composition in montane rainforests in Veracruz and Chiapas, Mexico. For. Ecol. Manag. 254, 276-290 (2008).

70. Williams-Linera, G., Alvarez-Aquino, C. \& Pedraza, R. A. Forest restoration in the tropical montane cloud forest belt of central veracruz, Mexico. Tropical Montane Cloud Forests: Science for Conservation and Management (2011). https://doi.org/10.1017/ CBO9780511778384.067

71. Cole, R. J., Litton, C. M., Koontz, M. J. \& Loh, R. K. Vegetation recovery 16 years after feral pig removal from a wet Hawaiian forest. Biotropica 44, 463-471 (2012).

72. Cole, R. J. \& Litton, C. M. Vegetation response to removal of non-native feral pigs from Hawaiian tropical montane wet forest. Biol. Invasions 16, 125-140 (2014).

73. Gould, R. K., Mooney, H., Nelson, L., Shallenberger, R. \& Daily, G. C. Restoring native forest understory: The influence of ferns and light in a Hawaiian experiment. Sustainability 5, 1317-1339 (2013).

74. Hart, P. J. Tree growth and age in an ancient Hawaiian wet forest: Vegetation dynamics at two spatial scales. J. Trop. Ecol. 26, $1-11(2010)$

75. Ibanez, T. \& Hart, P. J. Spatial patterns of tree recruitment in a montane Hawaiian wet forest after cattle removal and pig population control. Appl. Veg. Sci. 23, 197-209 (2020).

76. Pinto, J. R., Davis, A. S., Leary, J. J. K. \& Aghai, M. M. Stocktype and grass suppression accelerate the restoration trajectory of Acacia koa in Hawaiian montane ecosystems. New For. 46, 855-867 (2015).

77. Hylander, K. \& Nemomissa, S. Complementary roles of home gardens and exotic tree plantations as alternative habitats for plants of the Ethiopian montane rainforest [Roles complementarios de jardines domesticos y plantaciones de 'arboles ex́oticos como habitats alternativos para plan. Conserv. Biol. 23, 400-409 (2009).

78. Roose, E. \& Ndayizigiye, F. Agroforestry, water and soil fertility management to fight erosion in tropical mountains of Rwanda. Soil Technol. 11, 109-119 (1997).

79. Uhlig, S. K. Tropical mountain ecology in Ethiopia as a basis for conservation, management and restoration. Trop. For. Transit. https://doi.org/10.1007/978-3-0348-7256-0_8 (1992).

80. Carilla, J. \& Grau, H. R. 150 years of tree establishment, land use and climate change in Montane grasslands, Northwest Argentina. Biotropica 42, 49-58 (2010).

81. Camelo, O. J., Urrego, L. E. \& Orrego, S. A. Environmental and socioeconomic drivers of woody vegetation recovery in a humanmodified landscape in the Rio Grande basin (Colombian Andes). Restor. Ecol. 25, 912-921 (2017).

82. Wilson, S. J., Coomes, O. T. \& Dallaire, C. O. The `ecosystem service scarcity path' to forest recovery: A local forest transition in the Ecuadorian Andes. Reg. Environ. Change 19, 2437-2451 (2019).

83. Middendorp, R. S., Pérez, A. J., Molina, A. \& Lambin, E. F. The potential to restore native woody plant richness and composition in a reforesting landscape: A modeling approach in the Ecuadorian Andes. Landsc. Ecol. 31, 1581-1599 (2016).

84. Bingli, L., Weide, Z. \& Rongyuan, Z. The rebirth of tropical rainforest - ecological restoration planning for Sanda Mountain of Xishuangbanna, China. Landsc. Archit. Front. 8, 108-125 (2020).

85. Byers, A. C. Alpine habitat conservation and restoration in tropical and sub-tropical high mountains. Routledge Handb. Ecol. Environ. Restor. https://doi.org/10.4324/9781315685977 (2017).

86. Guariguata, M. R. Restoring tropical montane forests. in Forest Restoration in Landscapes: Beyond Planting Trees 298-302 (2005). https://doi.org/10.1007/0-387-29112-1_43

87. González-Espinosa, M. et al. Restoration of forest ecosystems in fragmented landscapes of temperate and montane tropical Latin America. in Biodiversity Loss and Conservation in Fragmented Forest Landscapes: The Forests of Montane Mexico and Temperate South America 335-369 (2007)

88. Newmark, W. D., Jenkins, C. N., Pimm, S. L., McNeally, P. B. \& Halley, J. M. Targeted habitat restoration can reduce extinction rates in fragmented forests. Proc. Natl. Acad. Sci. U.S.A. 114, 9635-9640 (2017). 
89. Holl, K. D. Research directions in tropical forest restoration. Ann. Mo. Bot. Gard. 102, 237-250 (2017).

90. Roose, E., Ndayizigiye, F. \& Sekayange, L. Agroforestry and land husbandry in Rwanda. How to restore the acid soils productivity in tropical mountains densely populated? [Lagroforesterie et la GCES au Rwanda. Comment restaurer la productivite des terres acides dans une region tropicale de montagn. Cah. ORSTOM Ser. Pedol. 28, 327-349 (1993).

91. Diego Leon, J., Isabel Gonzalez, M. \& Fernando Gallardo, J. Biogeochemical cycles in natural forest and conifer plantations in the high mountains of Colombia. Rev. Biol. Trop. 59, 1883-1894 (2011).

92. Chazdon, R. L. et al. Erratum: Fostering natural forest regeneration on former agricultural land through economic and policy interventions. Environ. Res. Lett. 15, 043002. https://doi.org/10.1088/1748-9326/ab79e6 (2020).

93. Miranda-Castro, L. \& Padrón, S. From the mountains to the sea: Restoring shaded coffee plantations to protect tropical coastal ecosystems. in Proceedings of MTS/IEEE OCEANS, 2005 vol. 2005 662-669 (2005).

94. Hakim, L. \& Miyakawa, H. Integrating ecosystem restoration and development of recreation sites in degraded tropical mountain areas in East Java, Indonesia. AIP Conf. Proc. 2019 (2018).

95. Gilroy, J. J. et al. Cheap carbon and biodiversity co-benefits from forest regeneration in a hotspot of endemism. Nat. Clim. Change 4, 503-507 (2014).

96. Räger, N., Williams-Linera, G. \& Huth, A. Modeling the dynamics of tropical montane cloud forest in central Veracruz, Mexico. Tropical Montane Cloud Forests: Science for Conservation and Management (2011). https://doi.org/10.1017/CBO9780511778384. 063

97. Chen, T.-S., Lin, C.-Y., Ho, S.-H., Lin, C.-Y. \& Yang, Y.-L. Evaluation of priority order for the landslide treatment using biodiversity index in a watershed. J. Chin. Soil Water Conserv. 45, 119-127 (2014).

98. Liu, H., Yi, Y., Blagodatsky, S. \& Cadisch, G. Impact of forest cover and conservation agriculture on sediment export: A case study in a montane reserve, south-western China. Sci. Total Environ. 702, 134802 (2020).

99. Crespo, P. et al. Land use change impacts on the hydrology of wet Andean paramo ecosystems. in Status and Perspectives of Hydrology in Small Basins (Proceedings of the Workshop held at Goslar-Hahnenklee, Germany, 30 March-2 April 2009) (IAHS, 2010). doi:https://doi.org/10.13140/2.1.5137.6320

100. Muñoz-Villers, L. E. \& McDonnell, J. J. Land use change effects on runoff generation in a humid tropical montane cloud forest region. Hydrol. Earth Syst. Sci. 17, 3543-3560 (2013).

101. Calle, Z., Henao-Gallego, N., Giraldo, C. \& Armbrecht, I. A comparison of vegetation and ground-dwelling ants in abandoned and restored gullies and landslide surfaces in the Western Colombian Andes. Restor. Ecol. 21, 729-735 (2013).

102. Posada, J. M., Mitche, T. \& Cavelier, J. Cattle and weedy shrubs as restoration tools of tropical montane rainforest. Restor. Ecol. 8, 370-379 (2000).

103. Lemenih, M. \& Teketay, D. Changes in soil seed bank composition and density following deforestation and subsequent cultivation of a tropical dry Afromontane forest in Ethiopia. Trop. Ecol. 47, 1-12 (2006).

104. Galindo, V., Calle, Z., Chará, J. \& Armbrecht, I. Facilitation by pioneer shrubs for the ecological restoration of riparian forests in the Central Andes of Colombia. Restor. Ecol. 25, 731-737 (2017).

105. Slocum, M. G., Aide, T. M., Zimmerman, J. K. \& Navarro, L. A strategy for restoration of montane forest in anthropogenic fern thickets in the Dominican Republic. Restor. Ecol. 14, 526-536 (2006).

106. Rurangwa, M. L., Matthews, T. J., Niyigaba, P., Tobias, J. A. \& Whittaker, R. J. Assessing tropical forest restoration after fire using birds as indicators: An afrotropical case study. For. Ecol. Manag. 10, 118765. https://doi.org/10.1016/j.foreco.2020.118765 (2020).

107. Gunaratne, A. M. T. A., Gunatilleke, C. V. S., Gunatilleke, I. A. U. N., Madawala Weerasinghe, H. M. S. P. \& Burslem, D. F. R. P. Barriers to tree seedling emergence on human-induced grasslands in Sri Lanka. J. Appl. Ecol. 47, 157-165 (2010).

108. Le Stradic, S., Fernandes, G. W. \& Buisson, E. No recovery of campo rupestre grasslands after gravel extraction: implications for conservation and restoration. Restor. Ecol. 26, S151-S159 (2018).

109. Sanchez-De Leon, Y., Zou, X., Borges, S. \& Ruan, H. Recovery of native earthworms in abandoned tropical pastures. Conserv. Biol. 17, 999-1006 (2003).

110. Wilms, J. \& Kappelle, M. Frugivorous birds, habitat preference and seed dispersal in a fragmented Costa Rican montane oak forest landscape. in Ecology and conservation of neotropical montane oak forests 309-324 (Springer, 2006).

111. Shoo, L. P., Storlie, C., Vanderwal, J., Little, J. \& Williams, S. E. Targeted protection and restoration to conserve tropical biodiversity in a warming world. Glob. Change Biol. 17, 186-193 (2011).

112. Edwards, D. P., Massam, M. R., Haugaasen, T. \& Gilroy, J. J. Tropical secondary forest regeneration conserves high levels of avian phylogenetic diversity. Biol. Conserv. 209, 432-439 (2017).

113. Gutierrez-Chacon, C., Valderrama-A, C. \& Klein, A.-M. Biological corridors as important habitat structures for maintaining bees in a tropical fragmented landscape. J. Insect Conserv. 24, 187-197 (2020).

114. Kattan, G. H., Correa, D., Escobar, F. \& Medina, C. Leaf-litter arthropods in restored forests in the Colombian Andes: A comparison between secondary forest and tree plantations. Restor. Ecol. 14, 95-102 (2006).

115. Davies, R. W., Edwards, D. P. \& Edwards, F. A. Secondary tropical forests recover dung beetle functional diversity and trait composition. Anim. Conserv. 23, 617-627 (2020).

116. Marian, F. et al. Conversion of Andean montane forests into plantations: Effects on soil characteristics, microorganisms, and microarthropods. Biotropica https://doi.org/10.1111/btp.12813 (2020).

117. Brancalion, P. H. S. \& Holl, K. D. Functional composition trajectory: A resolution to the debate between Suganuma, Durigan, and Reid. Restor. Ecol. 24, 1-3 (2016).

118. Matos, I. S., Eller, C. B., Oliveras, I., Mantuano, D. \& Rosado, B. H. P. Three eco-physiological strategies of response to drought maintain the form and function of a tropical montane grassland. J. Ecol. https://doi.org/10.1111/1365-2745.13481 (2020).

119. Eller, C. B., Lima, A. L. \& Oliveira, R. S. Cloud forest trees with higher foliar water uptake capacity and anisohydric behavior are more vulnerable to drought and climate change. New Phytol. 211, 489-501 (2016).

120. Barnes, A. D. \& Chapman, H. M. Dispersal traits determine passive restoration trajectory of a Nigerian montane forest. Acta Oecol. 56, 32-40 (2014).

121. Dimson, M. \& Gillespie, T. W. Trends in active restoration of tropical dry forest: Methods, metrics, and outcomes. For. Ecol. Manage. 467, 118150 (2020).

122. Gann, G. D. et al. International principles and standards for the practice of ecological restoration. Second edition. Restor. Ecol. 27, S1-S46 (2019).

123. Wilson, S. J. \& Rhemtulla, J. M. Acceleration and novelty: Community restoration speeds recovery and transforms species composition in Andean cloud forest. Ecol. Appl. 26, 203-218 (2016).

124. Muñiz-Castro, M. A. et al. Distance effect from cloud forest fragments on plant community structure in abandoned pastures in Veracruz, Mexico. J. Trop. Ecol. 22, 431-440 (2006).

125. Van Do, T., Osawa, A. \& Thang, N. T. Recovery process of a mountain forest after shifting cultivation in Northwestern Vietnam. For. Ecol. Manag. 259, 1650-1659 (2010).

126. Joshua Atondo-Bueno, E., Bonilla-Moheno, M. \& Lopez-Barrera, F. Cost-efficiency analysis of seedling introduction vs. direct seeding of Oreomunnea mexicana for secondary forest enrichment. For. Ecol. Manag. 409, 399-406 (2018).

127. Trujillo-Miranda, A. L., Toledo-Aceves, T., Lopez-Barrera, F. \& Guenter, S. Tree diversity and timber productivity in planted forests: Pinus patula versus mixed cloud forest species. New For. https://doi.org/10.1007/s11056-020-09787-1 (2020). 
128. Gallegos, S. C., Hensen, I., Saavedra, F. \& Schleuning, M. Bracken fern facilitates tree seedling recruitment in tropical firedegraded habitats. For. Ecol. Manag. 337, 135-143 (2015).

129. Peláez-Silva, J. A., León-Peláez, J. D. \& Lema-Tapias, A. Conifer tree plantations for land rehabilitation: An ecological-functional evaluation. Restor. Ecol. 27, 607-615 (2019).

130. Ortega-Pieck, A., López-Barrera, F., Ramírez-Marcial, N. \& García-Franco, J. G. Early seedling establishment of two tropical montane cloud forest tree species: The role of native and exotic grasses. For. Ecol. Manag. 261, 1336-1343 (2011).

131. Muniz-Castro, M.-A. et al. Restoring montane cloud forest: Establishment of three Fagaceae species in the old fields of central Veracruz, Mexico. Restor. Ecol. 23, 26-33 (2015).

132. Zhang, Z. H., Hu, G., Zhu, J. D. \& Ni, J. Stand structure, woody species richness and composition of subtropical karst forests in Maolan, south-west China. J. Trop. For. Sci. 24, 498-506 (2012).

133. Garcia-De La Cruz, Y., Lopez-Barrera, F. \& MariaRamos-Prado, J. Germination and seedling emergence of four endangered oak species. Madera y Bosques 22, 77-87 (2016).

134. Bare, M. C. \& Ashton, M. S. Growth of native tree species planted in montane reforestation projects in the Colombian and Ecuadorian Andes differs among site and species. New For. 47, 333-355 (2016).

135. Borja, P., Molina, A., Govers, G. \& Vanacker, V. Check dams and afforestation reducing sediment mobilization in active gully systems in the Andean mountains. CATENA 165, 42-53 (2018).

136. Gomez-Ruiz, P. A., Saenz-Romero, C. \& Lindig-Cisneros, R. Early performance of two tropical dry forest species after assisted migration to pine-oak forests at different altitudes: strategic response to climate change. J. For. Res. 31, 1215-1223 (2020).

137. Toledo-Aceves, T. \& Del-Val, E. Do plant-herbivore interactions persist in assisted migration plantings? Restor. Ecol. 29, (2020).

138. Urgiles, N. et al. Application of mycorrhizal roots improves growth of tropical tree seedlings in the nursery: A step towards reforestation with native species in the Andes of Ecuador. New For. 38, 229-239 (2009).

139. Braasch, M., Garcia-Barrios, L., Ramirez-Marcial, N., Huber-Sannwald, E. \& Cortina-Villar, S. Can cattle grazing substitute fire for maintaining appreciated pine savannas at the frontier of a montane forest biosphere-reserve?. Agric. Ecosyst. Environ. 250, 59-71 (2017).

140. Hernandez-Ladron De Guevara, I., Rojas-Soto, O. R., Lopez-Barrera, F., Puebla-Olivares, F. \& Diaz-Castelazo, C. Seed dispersal by birds in a cloud forest landscape in central Veracruz, Mexico: Its role in passive restoration. Rev. Chil. Hist. Nat. 85, 89-100 (2012).

141. Holl, K. D., Loik, M. E., Lin, E. H. V. \& Samuels, I. A. Tropical montane forest restoration in Costa Rica: Overcoming barriers to dispersal and establishment. Restor. Ecol. 8, 339-349 (2000).

142. Derroire, G., Coe, R. \& Healey, J. R. Isolated trees as nuclei of regeneration in tropical pastures: Testing the importance of nichebased and landscape factors. J. Veg. Sci. 27, 679-691 (2016).

143. Rhoades, C. C., Eckert, G. E. \& Coleman, D. C. Effect of pasture trees on soil nitrogen and organic matter: Implications for tropical montane forest restoration. Restor. Ecol. 6, 262-270 (1998).

144. Sheldon, K. S. \& Nadkarni, N. M. The use of pasture trees by birds in a tropical montane landscape in Monteverde, Costa Rica. J. Trop. Ecol. 29, 459-462 (2013).

145. Sprenkle-Hyppolite, S. D., Latimer, A. M., Young, T. P. \& Rice, K. J. Landscape factors and restoration practices associated with initial reforestation success in Haiti. Ecol. Restor. 34, 306-316 (2016).

146. Pang, C.-C., Ma, X.K.-K., Hung, T.T.-H. \& Hau, B.C.-H. Early ecological succession on landslide trails, Hong Kong, China. Ecoscience 25, 153-161 (2018).

147. Scowcroft, P. G. \& Jeffrey, J. Potential significance of frost, topographic relief, and Acacia koa stands to restoration of mesic Hawaiian forests on abandoned rangeland. For. Ecol. Manag. 114, 447-458 (1999).

148. Zahawi, R. A. Establishment and growth of living fence species: An overlooked tool for the restoration of degraded areas in the tropics. Restor. Ecol. 13, 92-102 (2005).

149. Dhakal, B., Pinard, M. A., Gunatilleke, I. A. U. N., Gunatilleke, C. V. S. \& Burslem, D. F. R. P. Strategies for restoring tree seedling recruitment in high conservation value tropical montane forests underplanted with cardamom. Appl. Veg. Sci. 18, 121-133 (2015).

150. Wilson, S. J. \& Coomes, O. T. 'Crisis restoration' in post-frontier tropical environments: Replanting cloud forests in the Ecuadorian Andes. J. Rural Stud. 67, 152-165 (2019).

151. Pethiyagoda, R. S. \& Manamendra-Arachchi, K. Endangered anurans in a novel forest in the highlands of Sri Lanka. Wildl. Res. 39, 641-648 (2012).

152. Del Castillo, R. F. \& Blanco-Macías, A. Secondary succession under a slash-and-burn regime in a tropical montane cloud forest: soil and vegetation characteristics. Biodivers. loss Conserv. Fragm. For. landscapes. For. Mont. Mex. Temp. South Am. CABI, Wallingford, Oxfordshire, UK 158-180 (2007).

153. Bautista-Cruz, A., Del Castillo, R. F., Etchevers-Barra, J. D., Gutiérrez-Castorena, M. D. C. \& Baez, A. Selection and interpretation of soil quality indicators for forest recovery after clearing of a tropical montane cloud forest in Mexico. For. Ecol. Manag. 277, 74-80 (2012).

154. Sarmiento, L., Llambí, L. D., Escalona, A. \& Marquez, N. Vegetation patterns, regeneration rates and divergence in an old-field succession of the high tropical Andes. Plant Ecol. 166, 145-156 (2003).

155. Raman, T. R. S. Effects of habitat structure and adjacent habitats on birds in tropical rainforest fragments and shaded plantations in the Western Ghats, India. Biodivers. Conserv. 15, 1577-1607 (2006).

156. Gunaratne, A. M. T. A., Gunatilleke, C. V. S., Gunatilleke, I. A. U. N., Madawala, H. M. S. P. \& Burslem, D. F. R. P. Overcoming ecological barriers to tropical lower montane forest succession on anthropogenic grasslands: Synthesis and future prospects. For. Ecol. Manag. 329, 340-350 (2014).

157. Mendoza-Vega, J., Ku-Quej, V. M., Messing, I. \& Pérez-Jiménez, J. C. Effects of native tree planting on soil recovery in tropical montane cloud forests. For. Sci. 66, 700-711 (2020).

158. Calle, A. \& Holl, K. D. Riparian forest recovery following a decade of cattle exclusion in the Colombian Andes. For. Ecol. Manag. 452, 117563 (2019).

159. Holl, K. D. Factors limiting tropical rain forest regeneration in abandoned pasture: Seed rain, seed germination, microclimate, and soil. Biotropica 31, 229-242 (1999).

160. Mullah, C. J. A., Klanderud, K., Totland, O. \& Kigomo, B. Recovery of plant species richness and composition in an abandoned forest settlement area in Kenya. Restor. Ecol. 52, 77-87 (2011).

161. Liu, X., Lu, Y., Yang, Z. \& Zhou, Y. Regeneration and development of native plant species in restored mountain forests, Hainan Island, China. Mt. Res. Dev. 34, 396-404 (2014).

162. Gunaratne, A. M. T. A., Gunatilleke, C. V. S., Gunatilleke, I. A. U. N., Weerasinghe, H. M. S. P. M. \& Burslem, D. F. R. P. Release from root competition promotes tree seedling survival and growth following transplantation into human-induced grasslands in Sri Lanka. For. Ecol. Manag. 262, 229-236 (2011).

163. Cole, R. J., Holl, K. D., Keene, C. L. \& Zahawi, R. A. Direct seeding of late-successional trees to restore tropical montane forest. For. Ecol. Manag. 261, 1590-1597 (2011).

164. Alvarez-Aquino, C., Williams-Linera, G. \& Newton, A. C. Experimental native tree seedling establishment for the restoration of a Mexican cloud forest. Restor. Ecol. 12, 412-418 (2004). 
165. Joshi, A. A., Ratnam, J. \& Sankaran, M. Frost maintains forests and grasslands as alternate states in a montane tropical forest-grassland mosaic; But alien tree invasion and warming can disrupt this balance. J. Ecol. https://doi.org/10.1111/1365-2745. 13239 (2019).

166. Singh, K. P., Mandal, T. N. \& Tripathi, S. K. Patterns of restoration of soil physicochemical properties and microbial biomass in different landslide sites in the Sal forest ecosystem of Nepal Himalaya. Ecol. Eng. 17, 385-401 (2001).

167. Wilcke, W. et al. Soil properties on a chronosequence of landslides in montane rain forest, Ecuador. CATENA 53, 79-95 (2003).

168. Diaz-Garcia, J. M., Pineda, E., Lopez-Barrera, F. \& Moreno, C. E. Amphibian species and functional diversity as indicators of restoration success in tropical montane forest. Biodivers. Conserv. 26, 2569-2589 (2017).

169. Doust, S. J., Erskine, P. D. \& Lamb, D. Direct seeding to restore rainforest species: Microsite effects on the early establishment and growth of rainforest tree seedlings on degraded land in the wet tropics of Australia. For. Ecol. Manag. 234, 333-343 (2006).

170. Howorth, R. T. \& Pendry, C. A. Post-cultivation secondary succession in a Venezuelan lower montane rain forest. Biodivers. Conserv. 15, 693-715 (2006).

171. Gomes, L. G. L., Oostra, V., Nijman, V., Cleef, A. M. \& Kappelle, M. Tolerance of frugivorous birds to habitat disturbance in a tropical cloud forest. Biol. Conserv. 141, 860-871 (2008).

172. Cole, R. J., Holl, K. D. \& Zahawi, R. A. Seed rain under tree islands planted to restore degraded lands in a tropical agricultural landscape. Ecol. Appl. 20, 1255-1269 (2010).

173. Pérez-García, O. \& del Castillo, R. F. Shifts in swidden agriculture alter the diversity of young fallows: Is the regeneration of cloud forest at stake in southern Mexico?. Agric. Ecosyst. Environ. 248, 162-174 (2017).

174. Gallegos, S. C. et al. Factors limiting montane forest regeneration in bracken-dominated habitats in the tropics. For. Ecol. Manag. 381, 168-176 (2016).

175. Riviere, J.-N. et al. Role of tree ferns in flowering plant settlement in the tropical montane rainforests of La Reunion (Mascarene Archipelago, Indian Ocean). Rev. D Ecol. TERRE LA VIE 63, 199-207 (2008).

176. Mohandass, D., Chhabra, T., Singh Pannu, R. \& Beng, K. C. Recruitment of saplings in active tea plantations of the Nilgiri mountains: Implications for restoration ecology. Trop. Ecol. 57, 101-118 (2016).

177. Wassie, A., Bongers, F., Sterck, F. J. \& Teketay, D. Church forests-relics of dry afromontane forests of Northern Ethiopia: opportunities and challenges for conservation and restauration. Degrad. For. East. Africa Manag. Restor. 123-133 (2010).

178. Townsend, P. A. \& Masters, K. L. Lattice-work corridors for climate change: A conceptual framework for biodiversity conservation and social-ecological resilience in a tropical elevational gradient. Ecol. Soc. https://doi.org/10.5751/ES-07324-200201 (2015).

179. Nogués-Bravo, D., Araújo, M. B., Errea, M. P. \& Martínez-Rica, J. P. Exposure of global mountain systems to climate warming during the 21st Century. Glob. Environ. Change 17, 420-428 (2007).

180. Pepin, N. et al. Elevation-dependent warming in mountain regions of the world. Nat. Clim. Change 5, 424-430 (2015).

181. Fadrique, B. et al. Widespread but heterogeneous responses of Andean forests to climate change. Nature 564, 207-212 (2018).

182. Peters, M. K. et al. Climate-land-use interactions shape tropical mountain biodiversity and ecosystem functions. Nature 568, 88-92 (2019).

183. Feeley, K. J. \& Rehm, E. M. Downward shift of montane grasslands exemplifies the dual threat of human disturbances to cloud forest biodiversity. Proc. Natl. Acad. Sci. 112, E6084-E6084 (2015).

184. Gómez-Ruiz, P. A., Sáenz-Romero, C. \& Lindig-Cisneros, R. Early performance of two tropical dry forest species after assisted migration to pine-oak forests at different altitudes: strategic response to climate change. J. For. Res. 31, 1215-1223 (2020).

185. Joppa, L. N. \& Pfaff, A. High and far: Biases in the location of protected areas. PLoS One 4, 1-6 (2009).

186. von Holle, B., Yelenik, S. \& Gornish, E. S. Restoration at the landscape scale as a means of mitigation and adaptation to climate change. Curr. Landsc. Ecol. Rep. 5, 85-97 (2020).

187. Fischer, J., Riechers, M., Loos, J., Martin-Lopez, B. \& Temperton, V. M. Making the UN decade on ecosystem restoration a social-ecological endeavour. Trends Ecol. Evol. xx, 1-9 (2020).

188. Monitoring Task Force. Briefing note on the Task Force on Monitoring for the UN Decade on Ecosystem Restoration 2021-2030 (2020).

189. Elliott, S. The potential for automating assisted natural regeneration of tropical forest ecosystems. Biotropica 48, 825-833 (2016).

\section{Acknowledgements}

The authors acknowledge the help of Trisha Gopalakrishna, Jasper Verschuur and Charles Tebbutt on improving and commenting on the manuscript. Tina Christmann acknowledges the financial support by the Rhodes Trust during her PhD. This project was funding with UKRI-NERC funding to Imma Oliveras Menor (NE/S011811/1).

\section{Author contributions}

T.C. and I.O. jointly designed the study. T.C. conducted data analysis and led the writing of the manuscript under supervision of I.O.

\section{Competing interests}

The authors declare no competing interests.

\section{Additional information}

Supplementary Information The online version contains supplementary material available at https://doi.org/ 10.1038/s41598-021-03205-y.

Correspondence and requests for materials should be addressed to T.C.

Reprints and permissions information is available at www.nature.com/reprints.

Publisher's note Springer Nature remains neutral with regard to jurisdictional claims in published maps and institutional affiliations. 
(c) (i) Open Access This article is licensed under a Creative Commons Attribution 4.0 International cc) License, which permits use, sharing, adaptation, distribution and reproduction in any medium or format, as long as you give appropriate credit to the original author(s) and the source, provide a link to the Creative Commons licence, and indicate if changes were made. The images or other third party material in this article are included in the article's Creative Commons licence, unless indicated otherwise in a credit line to the material. If material is not included in the article's Creative Commons licence and your intended use is not permitted by statutory regulation or exceeds the permitted use, you will need to obtain permission directly from the copyright holder. To view a copy of this licence, visit http://creativecommons.org/licenses/by/4.0/.

(C) The Author(s) 2021 